\title{
Enfiteusis y desdoblamiento de la posesión de la tierra. Entre Europa y América
}

Emphyteusis and Divided Land Ownership. From Europe to América

\author{
Pablo F. Luna \\ Sorbonne Université y Centre de recherches historiques \\ (CRH-EHESS-CNRS), Francia \\ pablo.f.-luna@ehess.fr
}

\section{ReSUMEN:}

El desdoblamiento de la posesión de la tierra y las riquezas naturales se ha vuelto un asunto importante en la investigación histórica. Los estudios sobre las prácticas y los contratos enfitéuticos han abierto nuevas pistas para el análisis histórico y el conocimiento del presente en el mundo rural (y también en el urbano). Si el avance ha sido notorio en Europa, los historiadores latinoamericanos también han contribuido a desbrozar ese campo del saber. Al ser la perspectiva comparatista uno de los instrumentos metodológicos más eficaces, el objetivo del presente artículo es presentar los avances de la producción europea junto con los latinoamericanos y poner de realce los retos de investigación futuros, renovando enfoques, igualmente comparatistas, sobre asuntos como el espacio rural, la propiedad de la tierra y la producción agrícola, que están nuevamente sobre el tapete.

Palabras Clave: Enfiteusis, Desdoblamiento de posesión, Dominio, Propiedad, Crecimiento agrícola, Trabajo rural, Arrendamiento, Conflictividad rural.

\section{Abstract:}

The division of possession of land and natural wealth has become an important issue in historical research. Studies on emphyteutic practices and contracts have opened new ways for historical analysis and knowledge of the present, in the rural (and also in the urban) world. If the advance has been notable in Europe, Latin American historians have not been left behind and have also contributed to clearing this field of knowledge. As the comparative perspective is one of the most effective methodological instruments to progress together, the objective of this article has been precisely to present the progress of European production together with Latin American ones, and to highlight the research needs that follow from the comparison. We are convinced that it can be a useful way to renew approaches and promote future studies equally comparative, on issues such as rural areas, land ownership and agricultural production which are once again on the table.

KEYWORDS: Emphyteusis, Division of possession, Dominium, Property, Agricultural growth, Rural work, Land leasing, Rural conflict.

\section{INTRODUCCIÓN}

El estudio de las formas desdobladas de posesión de la tierra y las riquezas naturales es una cuestión en la que ha habido en los últimos veinte años importantes progresos. La producción historiográfica, especialmente europea aunque también latinoamericana, ha ampliado la perspectiva de los trabajos anteriores, integrando las mencionadas formas de posesión en su contexto económico y social y en su dinámica contractual. Por ello, el objetivo de este artículo es plantear la reflexión sobre el asunto, sabiendo que se trata de un trabajo que requiere esfuerzos colectivos. Desde ese punto de vista, nos parece que habría por lo menos tres cuestiones que considerar y que permitirían avanzar en nuestro cometido:

— En primer lugar, la necesidad de repensar el estatuto de la posesión o dominio ${ }^{1}$, que se implantó de manera práctica en las nacientes sociedades hispanoamericanas, desde el último tercio del siglo XVI, y el lugar que le cupo a la importación desde Europa de la enfiteusis y las formas desdobladas de posesión de la tierra y las riquezas naturales. ${ }^{2}$ 
- En segundo lugar, la revisión de las relaciones sociales de posesión o dominio, en un contexto de colonización, que dieron lugar a configuraciones regionales y procesos mineros, agrícolas y económicos. ${ }^{3}$ Las referidas formas contractuales europeas no llegaron a un territorio en donde no hubiera previamente ninguna forma de institucionalidad, procedimientos codificados o "derechos" de acceso a la tierra.

- En tercer lugar, el replantear la transición, desde el siglo XVIII, del dominio o posesión hacia la propiedad contemporánea, pasando por la desamortización y desvinculación (integrales o parciales), debidas a la acción del mercado o la voluntad política. La victoria de los propietarios a la que se asiste (en Europa y América), entre los siglos XVIII y XIX (Luna, 2006, 2017), debe ser analizada en Hispanoamérica tomando en cuenta las formas de posesión o dominio implantadas desde el siglo XVI ${ }^{4}$ y las formas híbridas que surgieron.

Fuera de ello, desearíamos fundamentar la lógica misma sobre la que se asienta este ejercicio comparatista. Para ello, entremos clara y directamente en materia. ¿Por qué interesarse en las formas que desdoblan la posesión o dominio de la tierra y las riquezas naturales, o sea las formas enfitéuticas, prácticas y jurídicas? Efectivamente, por qué hacerlo cuando se valoran sobre todo las ventajas de la propiedad absoluta, individual, segura, homogénea, moderna y privada, para garantizar (así se piensa) el crecimiento económico y material, así como la reducción de la pobreza. Es toda una teoría bien asentada (North, 1995; Deininger, 2003; Cheneval y De Soto, 2006; Sánchez, Fazio y López, 2007; Cordero, 2008), con forjadores iniciales desde el siglo XVIII y defensores durante los siglos XIX y XX; y es, además, lo que se preconiza hoy en día desde el Banco Mundial y otras instancias internacionales, cuando se señala (mirando los territorios más pobres del planeta) que se tienen que instaurar "claros" derechos de propiedad, para atraer capitales y lograr modernización. A lo que se agrega la condena, como signo de atraso, de las formas de posesión compartida, desdoblada, tradicional o colectiva, opuestas (se afirma) a la transformación definitiva de la tierra y las riquezas naturales en recursos económicos y verdaderos objetos de cambio. Pero ¿no es justamente ese unanimismo el que nos interpela, al observar sus resultados actuales?

En segundo lugar, otra pregunta necesaria. ¿Por qué los historiadores de nuestro continente americano se tendrían que interesar por ese tipo de cuestiones? ¿Sólo por curiosidad intelectual? Si hay razones de comprensión histórica, cabe señalar, asimismo, la existencia de motivos contemporáneos que el trabajo del historiador no debiera olvidar y que tendrían que estimularlo a poner la comprensión histórica al servicio de un mejor conocimiento del presente. Por eso, la propiedad de la tierra y los recursos naturales (en su formulación contemporánea), la problemática de la ruralidad, la producción agropecuaria y el futuro del campo y sus habitantes no deberían ser asuntos menores. Sobre todo cuando la sociedad lo solicita y es mejor que sea el mismo historiador quien hable de historia.

Ahora bien, si se trata de dar respuestas a interrogantes actuales, tampoco faltan las preguntas que formular. ¿Qué ha pasado para que, a pesar de numerosas "reformas agrarias" (incluso "revoluciones agrarias") desde los años 1950 - e incluso antes - , se hayan producido nuevas reconcentraciones de la propiedad de la tierra y de riquezas naturales, algunas de ellas de una amplitud hasta ahora desconocida? ${ }^{5}$ ¿Por qué razones, a pesar de su aparente fracaso, la "reforma agraria" (o una "auténtica reforma agraria" ${ }^{6}$ ) sigue siendo leitmotiv de los nuevos campesinados del continente, que son también nuevas capas sociales emergentes?

La historia de la posesión o dominio de la tierra y las riquezas naturales, en una visión de largo plazo y con instrumental comparatista, tiene mucho que ofrecer para contestar esas preguntas, por demasiado actuales que puedan parecernos. Pero el comparatismo tiene que sobrepasar los límites continentales y conjugar un ir y venir con otras experiencias, por ejemplo las del continente europeo, y no solamente. Para decirlo con toda claridad: existen formas de cesión de la tierra, de inversión de capitales, de conducción de empresas agrícolas, de creación de derechos, etc., que la creatividad humana concibió para momentos y espacios distintos, que pudieron "viajar" y que, en su práctica cotidiana, se mezclaron con sus homólogas autóctonas; y que conviene estudiar para mejor conocer el presente. 
Este artículo se divide en dos partes. En primer lugar, intentamos reconstituir un esquema útil que permita sintetizar lo que ya sabíamos de la enfiteusis y el desdoblamiento de la posesión, antes de las dos últimas décadas de progreso historiográfico, incorporando las contribuciones latinoamericanas. En segundo lugar, presentamos los principales logros de la investigación europea de las dos décadas recientes, en articulación con los logros de nuestro continente.

\section{LO QUE YA SABÍAMOS SOBRE ENFITEUSIS Y DESDOBLAMIENTO DE LA POSESIÓN}

Aquí distinguimos, grosso modo, cinco ejes que nos ayudan a explicar lo que ya conocíamos de la práctica enfitéutica, antes de los años 2000,incluso en el continente latinoamericano.

\subsection{Sobre la práctica y el contrato enfitéuticos}

Antes de los recientes progresos, ya sabíamos que la enfiteusis era una práctica de posesión de la tierra y las riquezas naturales, a veces una forma de unidad productiva, o también un tipo especial de contrato agrario y de disposición de los bienes. De origen griego (anterior al feudalismo), su expansión alcanzó toda Europa - mediterránea, central y oriental, e incluso las islas británicas - y no solamente la península ibérica. Situándose en el largo (o muy largo) plazo, esa práctica y contrato (escrito o verbal) se caracterizaban por el desdoblamiento de la posesión de los bienes inmuebles de la operación en dos dimensiones. Por un lado, el dominio directo (directum dominium, relativo al derecho eminente del poseedor - aunque no estrictamente equivalente-, forma superior de posesión). Por otro lado, el dominio útil (utile dominium, relativo al uso práctico, productivo, posesión inferior del productor/conductor directo, o intermediario), instaurando una dualidad de posesión (por lo menos) y un conjunto de reglas y mandatos (Clavero, 1980, 1986; Lemeunier, 1989; Peset, 1989; Congost, 2003). ${ }^{7}$

El poseedor directo aceptaba (o incluso propugnaba) el hecho práctico y mental de desprender la dimensión útil del bien bajo su dominio, con el fin de cederla a un enfiteuta - que era más que un simple usufructuario o locatario-, para que éste explotase dicho dominio útil, desde el punto de vista económico o productivo, gozando de la capacidad de disponer de él, incluso de venderlo (Peset, 1989; Von Wobeser, 1994; Rodríguez, 2007; Cordero y Aldunate, 2008), con autorización del poseedor directo (previa indemnización). Con esa operación, el dueño directo conservaba la posesión o dominio directo (de derecho) del bien, aparte de percibir una renta o canon e imponer obligaciones al enfiteuta o dueño útil, que podían ser reales o materiales; por ejemplo, la obligación de destinar tierras a cultivos como la viña y el olivo, la plantación de árboles frutales (Sanz, 1998) o la construcción de obras de irrigación. Pero también se imponían obligaciones simbólicas, de homenaje y reconocimiento de señorío. ${ }^{8}$

Si esa práctica y contrato antiguos estuvieron vinculados al señorío civil y eclesiástico, al confirmarse y extenderse (y por su estrecha relación al trabajo rural) también se fueron diferenciando y alejando de él, a veces gracias a conflictos y revueltas, o a la sombra de revoluciones, para volverse una forma duradera de estructura agraria, que transitó desde el Antiguo Régimen hacia la sociedad "moderna”. Ello equivale a decir que poco a poco se deshicieron de los atavíos feudales, homenajes, reconocimientos, servidumbres, etc., y pasaron de un sistema a otro como formas contractuales y productivas específicas (Pérez-Picazo, 1989). Con ello, el contrato enfitéutico se volvía un contrato "real", o sea relacionado con los elementos materiales de la posesión y la explotación económica, que se distinguía de la locación o arrendamiento a corto plazo, o de la aparcería en sus diferentes modalidades. En su evolución, dicho contrato pudo mudar de plumaje, mimetizarse o guarnecer su existencia, en un contexto de oposición entre poseedores y desposeídos, sin que faltaran los que le recordaran sus vínculos (y hasta sus orígenes) señoriales o medievales (Clavero, 1980). 


\subsection{Sobre sus mecanismos y funcionamiento}

También sabíamos anteriormente que la cesión del dominio útil podía suscitar controversias entre la superficie y el espacio cedidos, entre la posesión del suelo (y su explotación agrícola) y la construcción de elementos de vivienda, depósito, "oficinas", mejoras edificadas, entre otros. Esto también ocurría con la posesión de la planta o los árboles (y su duración como raíz) y la superficie sobre la que se habían plantado, o entre el goce del espacio y la superficie, por un lado, y las servidumbres, obligaciones o recargos fiscales, por otra parte. O también con la extensión de esa práctica y contrato en el medio urbano, o por el subsuelo, con la explotación minera y sus concesiones por la autoridad real. Con el tiempo se incorporarían otros problemas y agentes, entre ellos la autoridad estatal, pasando desde las regalías del rey hasta los gravámenes y cuotas del Estado moderno (independiente y republicano ${ }^{9}$ en el caso latinoamericano), los códigos civiles, sus defensores, o la regulación entre poseedores.

Fuera de la confusión, inducida por el vocabulario de los notarios o juristas (no siempre involuntariamente), o por los mismos agentes de las operaciones ${ }^{10}$, sabíamos que los usos y la costumbre habían modulado un contrato con matices, que le impregnaban una característica central: su capacidad para adaptarse (Saavedra, 1985; Clavero, 1986; Villares, 1989). Recordamos con ello que los contratos podían cambiar según la geografía, el clima, la demografía o las condiciones socioeconómicas, lo que los alejaba tanto del formalismo jurídico (pensar que la ley era la misma realidad) como de las presuntas exigencias sine qua non. Más bien, se tomaban en cuenta la correlación de fuerzas entre los participantes del contrato, sus intereses, victorias definitivas o pasajeras, compromisos inestables de duración limitada ${ }^{11}$, entre otros aspectos.

Por ello, se podía hablar de un itinerario específico o de una vida propia del contrato y la práctica enfitéuticos, que desafiaban al mundo institucional (o al Estado, más o menos fuerte) y se adaptaban al tipo de producción, al suelo, a la costumbre de los protagonistas sociales, con todas las asperidades de los conflictos de intereses ${ }^{12}$, lo que no siempre se prestaba a su fácil formalización legal. Para cada titular de dominio (directo o útil), el suyo era el más importante; la preponderancia del uno o la del otro variaba entre el derecho y la correlación de fuerzas, entre la posesión y el goce del bien, y no siempre se seguían los a priori del jurista.

\subsection{Sobre sus características principales}

Fuera de su adaptabilidad, el contrato y la práctica enfitéuticos supieron conservar dos características distintivas. En primer lugar, su durabilidad, en el largo (o muy largo) plazo ${ }^{13}$, a veces su naturaleza perpetua (por ejemplo, cuando servía para atraer a pobladores y su establecimiento), siempre ligada a las condiciones concretas del entorno (Serra, 1989). En segundo lugar, el desdoblamiento, admitido o deseado de la posesión (inclusive de fuentes hidrológicas, von Wobeser, 1983b), a cambio de un canon o censo enfitéutico ${ }^{14}$ de composición definida por el contrato (o impuesta por el dueño directo). A veces, el canon enfitéutico podía ser una parte de la cosecha, cedida al dueño directo por el útil, sin que ello significara que se hubiera pasado a la aparcería (Sanz, 1998).

Pero también, en ese último caso, eso revelaba que estábamos ante una forma de contrato y una práctica en que se reconocía que el trabajo aplicado por el enfiteuta o dueño útil en la tierra cedida quedaba retribuido gracias a la parte del producto que le correspondía a él y a su familia; o sea, su trabajo se había cristalizado en productos. Ello ocurría incluso en los contratos que en primer lugar se relacionaban con tipos de cultivos y con su posesión, en los que la referencia a la tierra donde se los plantaba iba a ser sólo ulterior y que ya se vinculara al reconocimiento de las mejoras introducidas en los campos y la tierra.

Con ello tocamos otro elemento importante, el de las mejoras (o perfectos) incorporados en el bien recibido en enfiteusis. Su realización podía ser una obligación impuesta al enfiteuta, pero cabe señalar que 
derivaba casi naturalmente del contrato, sobre todo cuando se trataba de tierras eriazas, por "romper" o desmontar, para transformarlas en cultivables o plantarlas con nuevos cultivos (Congost, 1989). A veces ocurría que esos perfectos se concretizaban en construcciones, en mantenimiento de canales, drenaje de campos, acondicionamiento de terrenos (aplanamiento de superficies), o en la urbanización del espacio rural (Serra, 1989). El dueño del útil que trabajaba empleaba su fuerza de trabajo al haber aceptado o pedido las tierras del contrato, pero también seguramente porque carecía de otros medios para acceder a tierras productivas, y sólo contaba con su trabajo (y el de su familia) o, en el caso de otro perfil sociológico rural, porque carecía de créditos o capitales para ampliar su unidad productiva. ${ }^{15}$

Por ello es importante señalar que se daba en esos perfectos otra de las singularidades de la enfiteusis, a saber: cada una de esas mejoras representaba la fijación material del trabajo del enfiteuta en su posesión útil. Es decir que se producía una forma de cristalización del esfuerzo en el tiempo y que (según la actividad) podía sedimentar el trabajo de varias generaciones. Ese hecho tuvo consecuencias tangibles en la materialidad de los bienes del contrato, pero también en la percepción que los dueños útiles podían formarse (certidumbres y mentalidades), lo que afirmaba y consolidaba la idea de que su trabajo (y el de sus antepasados) se había materializado y consolidado en la posesión útil. Esa era, por cierto, la cuestión que planteaba el reconocimiento real y jurídico de los referidos perfectos, mediante conflictos y pleitos, también como fruto de la diferenciación social en el mundo rural (Serra, 1989). En esa línea (al sentirse también poseedores o por otras razones), los enfiteutas cuestionaron incluso la legalidad de posesión de los dueños directos, en juicios en los que exigieron la presentación de los verdaderos o "legítimos títulos" de posesión del dominio directo (Congost, 2000).

También hubo una forma de autonomización del dominio útil, con exigencia de pleno reconocimiento reclamada al dueño directo. Con mayor claridad que John Locke, el magistrado asturiano Gaspar de Jovellanos (estudioso de las relaciones entre la posesión de la tierra y el trabajo en ella) observó tal evolución, durante el siglo XVIII, en varios territorios peninsulares (Anes, 1995; Luna, 2006, 2012). Claro, no fue el único en constatarlo, pero pudo verlo directa y prácticamente (durante sus viajes por la geografía peninsular), con los intereses en conflicto, durante las décadas centrales del siglo XVIII, en torno a la forma enfitéutica foro, en el norte y noroeste de la península y en la favorable evolución agrícola catalana (y aragonesa). De allí su propuesta de generalizar la enfiteusis, contra el estancamiento y vinculación de la tierra, en pro del progreso agrícola por todo el territorio (Luna, 2006, 2012).

\subsection{Sobre los vínculos existentes entre demografía y enfiteusis}

Sabíamos que el contrato y la práctica enfitéuticos se habían extendido vinculados a factores demográficos. En primer lugar, habían sido utilizados por el señorío civil y eclesiástico, para establecer duraderamente asentamientos familiares, en un contexto de despoblamiento. Por ejemplo, en los procesos de "reconquista" ibérica (Lemeunier, 1989), como instrumento de ocupación y defensa militar. En segundo lugar, el contrato y la práctica enfitéuticos habían sido utilizados luego de pestes y epidemias, o después de conflictos o guerras, como la de los Treinta Años, por ejemplo, en Francia o en los devastados territorios germánicos (Béaur, 2003), o como factor de reocupación después de la salida masiva de grupos no cristianos, como ocurrió después de 1609 en el Reino de Valencia, luego de la expulsión de los moriscos (Gil, 1988; Ardit, 2012). Eran casos de debilitamiento del señorío (Ferrer, 1989). También hubo ejemplos que confirmaban la regla por defecto. Por ejemplo, luego de la expulsión de los jesuitas y el abandono de su práctica enfitéutica pobladora, con el vaciamiento de espacios densamente ocupados y explotados económicamente (Canales y Muñoz, 2001, 2002). El poblamiento rural o la "colonización" interna, en su variedad de objetivos, fueron hasta los siglos XIX y XX motivos para la puesta en práctica también en América de la enfiteusis (Pérez-Picazo, 1989). 
Sin embargo, también conocíamos un ejemplo contradictorio, en el mismo continente americano. Los conquistadores y colonos castellanos, impregnados de derecho castellano (aunque no de todo el derecho castellano), orientados por sus intereses y guiados por su práctica peninsular, según su lugar de origen, dieron otras soluciones a la catástrofe demográfica indígena de los siglos XVI y XVII. Claro, nos hallábamos en contextos diferentes e inéditos, en el cuadro del primer proceso de colonización moderno. ${ }^{16}$ Pero conviene no minimizar que los vencidos sobrevivientes de la conquista americana no fuesen transformados en enfiteutas, como práctica general ${ }^{17}$, por los colonizadores castellanos. ${ }^{18}$

También se había supuesto que la presión ejercida por demografías activas podía reducir el alcance de las prácticas enfitéuticas y cuestionar su aplicación pasada. $\mathrm{O}$ sea, que el crecimiento de la población, el "hambre de tierras" y la competencia podían cuestionar los contratos enfitéuticos de largo plazo y promover su reemplazo por contratos de arrendamiento a corto plazo (ver más adelante). Sabíamos que había casos en que la enfiteusis podía conciliarse con poblaciones numerosas o crecientes, aunque ello se tradujera en el fraccionamiento de la superficie y el control de la posesión. Se pensaba, asimismo, que el trabajo del enfiteuta permitía aumentar la producción y la riqueza económica, al tiempo que se señalaban las reservas del caso y se mantenía prudencia frente a la automática identificación entre enfiteusis, dinamismo demográfico y crecimiento productivo.

\subsection{Sobre los vínculos entre enfiteusis y crecimiento agrícola}

Antes de 2000 sabíamos, entonces, que la demografía por sí misma no bastaba para explicar el auge productivo; lo mismo ocurría con los property rights. Se pensaba que el crecimiento agrícola dependía de muchos factores, aunque ya se notara la tendencia a otorgarles a las "instituciones" el papel clave (North, 1995). También se habían cuestionado, práctica y teóricamente, las vías "únicas" o los modelos ineludibles ${ }^{19}$ para el crecimiento económico (Vilar, 1982). Dentro de la diversidad de factores, cada uno según su peso relativo, se solían citar el vigor de la demanda (local, interna, o más ampliamente "nacional" o “internacional”, según el momento), la tecnología, la voluntad o la posibilidad de invertir capitales por parte de los dueños directos, la urbanización, los precios, entre otros. Para la enfiteusis, práctica y contrato, prevalecía el método vilariano-labroussien de situarlos en su contexto socioeconómico, como otras prácticas y contratos afines, para medir su influencia en los procesos productivos.

Los trabajos de Pierre Vilar sobre Cataluña (Vilar, 1962) mostraban que el enriquecimiento global aunque desigual, gracias a la viña, podía conducir a sus beneficiarios a cuestionar la legalidad, la lógica y los contratos que lo habían permitido, e intentar degenerarlos o "desnaturalizarlos" (Serra, 1989). Es decir que esos beneficiarios podían intentar deshacerse de una enfiteusis que les había permitido acceder a una forma de posesión directa, otrora cedida a ellos en posesión útil y ahora cedida por ellos a nuevos dueños útiles. Para esos nuevos señores directos o cuasi-directos lo esencial era transformar el contrato en arrendamiento a corto plazo o aparcería, para acrecentar su parte de la cosecha y aumentar beneficios, olvidando a los enfiteutas del momento. Es decir, buscaban suprimir, sin escrúpulo ni remordimiento, la práctica y el contrato que les había permitido enriquecerse anteriormente, al no corresponder ya a sus nuevos intereses.

Era un hilo central para explicar los vínculos entre enfiteusis y crecimiento agrícola, sin reducirlos a exigencias institucionales o de property rights legales, u otros factores "únicos". Pero Pierre Vilar también había subrayado, al observar la práctica de los dueños útiles, que esos grupos habían transformado la enfiteusis y extendían su influencia, para acceder a la tierra y su explotación económica. ${ }^{20}$ Por ello, se podía hablar de actitudes diferenciales ante la enfiteusis, según el lugar social de sus protagonistas, si eran poseedores directos o cuasi-directos ya establecidos o si eran capas emergentes del campesinado. Ello significaba que la práctica enfitéutica no era ni neutra ni ajena al conflicto de clases y su dinámica, dentro del arsenal de la explotación del trabajo de los desposeídos (o la autoexplotación) y su resistencia. 


\section{LOS LOGROS DE LA INVESTIGACIÓN HISTÓRICA RECIENTE}

La investigación reciente sobre desdoblamiento y enfiteusis profundiza asuntos estudiados, los cuestiona y formula nuevos problemas y desafíos; los presentamos en seis rúbricas.

\subsection{Sobre enfiteusis y desdoblamientos ocultos}

Recientemente se han realizado trabajos sobre contratos que no fueron considerados como enfitéuticos, a pesar de serlo en la práctica, así como otros sobre la voluntad y la acción de determinados protagonistas para que sus contratos, aunque no siendo enfitéuticos, fuesen considerados y reconocidos como tales.

Se han detectado contratos que, sin llevar el rótulo de enfiteusis, satisfacían sus dos características: la durabilidad y el desdoblamiento de la posesión en dominios. Fuera de algunas formas sin epíteto enfitéutico ya conocidas, en los espacios ibéricos, germánicos, griegos, italianos o suizos (Clavero, 1986; Biagioli, 2003; Argyrou, 2003; Aymard, 2011; Barbot, Lorenzetti y Morelli, 2012; Santos y Serrao, 2013), se ha puesto en evidencia, por ejemplo en Francia, una variedad de contratos de tipo enfitéutico. Prolongando una investigación sobre contratos agrarios (Béaur, 2003), su autor ha elaborado un mapa con unos veinte contratos de corte enfitéutico, a lo largo de la geografía francesa, sin el adjetivo o rótulo que los delate. Se trata del albergement (en las regiones del Delfinado y Saboya), de los baux à rente foncière, contratos de arrendamiento inmueble, o los baux d'héritage, contratos de herencia (en la región bordelesa), de los baux à rente, contratos de arriendo a largo plazo (en la zona de influencia del Código Consuetudinario Parisino ${ }^{21}$ ) o de los baillettes, pequeños contratos, de la zona de Poitiers. Lo mismo ocurre con los abenevis de Forez (región central del departamento de Loira), que abrían derechos de posesión enfitéuticos sobre el agua del río Loira (Béaur, 2018). ${ }^{22}$ Otros estudios han hallado resultados similares para otros territorios franceses. ${ }^{23}$ Ello nos interroga sobre lo que ya dijimos (en la primera parte), respecto de los errores de vocabulario (o de noción) que nos hacen ignorar formas enfitéuticas, al confundir el nombre con el contenido; como ocurre con el sustantivo "arrendamiento" y el verbo "arrendar". ${ }^{24}$

Pero eso nos recuerda, también, que el reconocimiento de un contrato como enfitéutico puede ser un instrumento astutamente utilizado por algunos. Así ocurrió en la región de Alsacia con el hoflehn, un contrato designado por una voz que traduce "desnaturalización" o usurpación hecha por campesinos, al lograr que se reconociera como enfitéuticos sus contratos de arrendamiento a corto plazo (Boehler, 2018), para agrandar sus posesiones, a expensas del señorío civil y eclesiástico alsaciano, muy debilitado con la Guerra de los Treinta años y que a pesar de su ulterior "reacción señorial” no logró recuperar las tierras. Luego, la Revolución francesa confirmó a esos campesinos poseedores y a sus descendientes como dueños plenos, es decir como propietarios.

Pero no siempre ganan los labradores astutos, además de que, podríamos agregar, no es enfiteusis todo lo que brilla. Por ejemplo, el contrato domaine congéable, tenencia derogable, de la región francesa de Bretaña (especialmente la Baja Bretaña) y las reclamaciones para el reconocimiento del trabajo incorporado al bien por su colono o conductor. Se trataba de un contrato precario, de arrendamiento de 9 años con posibilidad de desalojo del convenancier ou domainier, colono, casi instantánea, si así lo decidía el convenant poseedor. No había cesión de dominio útil de la tierra, pero si el poseedor quería poner fin al contrato debía reconocer y reembolsar las mejoras del colono (casas, depósitos, establos, etc.), o la introducción de plantas, consideradas como mejoras y posesión del colono o domainier (Guégan, 2018). A veces, ese contrato se asimilaba a la aparcería. Un contrato similar se puede hallar, por ejemplo, en el campo de Córdoba ${ }^{25}$ (región Río de la Plata): el comodato (Ferreyra, 2014). Los comodantes del siglo XIX eran poseedores absentistas, que cedían tierras a comodatarios, a veces verbalmente y por tiempo indefinido, a cambio de rentas y derechos; esos comodatarios se resistieron a las expulsiones, hasta que no se les pagara por sus mejoras. 
En situación comparable, en la isla de Madera (Portugal), el contrato denominado colonia (establecimiento para "romper" y adaptar tierras eriales) en una región productora de vino de exportación (Santos y Serrao, 2013; Camara, 2018) reúne características similares, pero con una conflictividad específica. Los colonos y sus abogados defensores quisieron, a mediados del siglo XIX, que su contrato fuese asimilado a la enfiteusis (como los campesinos alsacianos, ver más arriba). Querían aprovechar la larga duración del contrato para evitar ser expulsados por los poseedores y que se reconocieran sus mejoras. Sin embargo, las sutilezas del Código Civil portugués ( $\mathrm{y}$ de los liberales portugueses de entonces ${ }^{26}$ ), las negociaciones directas entre poseedores y colonos, el contexto internacional (crecimiento de la demanda) y las perspectivas de mejoras técnicas y capitalización de fincas lograron diluir tales gestiones. ${ }^{27}$

\subsection{Debajo de la enfiteusis, la usurpación}

A veces la enfiteusis se presentó como opción política a favor de los desposeídos, poseedores precarios o enfiteutas amenazados de expulsión por los dueños directos. Varios casos europeos ilustraron esas tendencias, desde el siglo XVII. ${ }^{28}$ Pero también se podrían citar otras experiencias, por ejemplo, al inicio de la etapa independiente hispanoamericana ${ }^{29}$, cuando se preconizaba que la enfiteusis podía permitir una ocupación más justa del suelo. O casos que propugnaban un uso poblacional (y económico) de la enfiteusis (Barcos, 2013; Avila, 2014). Sin dejar a un lado, como constatación, que la práctica enfitéutica (incluso si luego desaparecía) podía tener como resultado, a mediano o largo plazo, un reparto más equilibrado de la posesión del suelo (Fandos, 2014). Sin embargo, en la misma América Latina pudo ocurrir todo lo contrario, o sea que la enfiteusis simbolizara el despojo de los sectores rurales (o urbanos) menos favorecidos. Esta es toda una investigación histórica por desarrollarse. ${ }^{30}$

Varias ofensivas de desposeimiento adoptaron un vocabulario enfitéutico, tal vez para ocultar un despojo inmediato o con la perspectiva de hacerlo más paulatino. ${ }^{31}$ Es lo que parece haber ocurrido, después de 1830, con los territorios que la legislación española había "reservado" o resguardado para las comunidades o grupos indígenas, dentro de la distribución de tierras y territorios (jurídica y práctica), legitimada y legalizada, especialmente con la "composición" de tierras, desde la última década del siglo XVI y de allí en adelante. Luego, el "hambre de tierras", estimulado por la demanda de productos agrícolas y las ganancias esperadas, siguió actuando durante el siglo XIX como factor de acaparamiento de "tierras indígenas", lo que suscitó el rechazo de los desposeídos, con formas pacíficas o violentas. La investigación latinoamericanista reciente lo ha demostrado, por ejemplo, en trabajos sobre el Noroeste argentino, en los que sobresale la complejidad de las estructuras de la propiedad en formación (Tell, 2011; Fandos y Teruel, 2009, 2012; Fandos, 2014; Teruel, 2019; Mata, 2019), o en estudios sobre la enfiteusis guatemalteca, cuya amplitud queda aún por verificar cuantitativamente, a pesar de los índices municipales presentados (Avila, 2014).

El territorio y las riquezas naturales, o el control del espacio, han atravesado un despojo en dos etapas. Primero, su transformación en "tierras públicas" (propuesta inicialmente bolivariana), con desconocimiento de los derechos de posesión anteriores. Luego, en un segundo momento, su cesión o transmisión a protagonistas o capitalistas (nacionales o extranjeros), con el fin de darles una explotación económica más intensiva y "racional". Pero sería indispensable conocer mejor cómo la adaptabilidad indígena y mestiza generó respuestas originales, si bien socialmente desiguales, al desposeimiento (Teruel, 2005; Menegus, 2009; Fandos, 2017; Farberman, 2019); aun cuando pudiesen los indígenas ser calificados de "bárbaros" ante unas usurpaciones presuntamente "civilizadoras".

Sin embargo, para convencernos de que la práctica enfitéutica, cuando se opta por ella, depende de los objetivos y de quién la propone y aplica, en determinadas realidades latinoamericanas actuales, por ejemplo en la Colombia de las recientes negociaciones de paz, se han manifestado propuestas favorables al contrato enfitéutico, para clarificar el panorama rural y actuar con justicia en el laberinto de la legislación sobre 
derechos de posesión. Se sugiere una generalización de la enfiteusis al conjunto del territorio colombiano ${ }^{32}$, tal como la propuso Jovellanos en la segunda mitad del siglo XVIII para el territorio español. Ello permitiría, explican, garantizar la posesión duradera del dominio útil, como derecho real, el reconocimiento de las mejoras y la transmisión hereditaria (Oñate, García y Ternera, 2018) ${ }^{33}$

\subsection{El tránsito de la enfiteusis a la locación (¿de ida y vuelta?)}

La vía de la enfiteusis a la locación o arrendamiento a corto plazo, con aumento de pensión, pero también el tránsito inverso, a veces "de regreso", de la locación hacia la enfiteusis, han formado parte de la investigación reciente. Tales movimientos, pacíficos o bruscos, han sido analizados para las penínsulas ibérica e italiana. Sabíamos que en Cataluña algunos dueños directos, o cuasi-directos (exdueños útiles o descendientes de dueños útiles), habían deseado abandonar la práctica enfitéutica (o sea, el haber cedido el dominio útil a sus enfiteutas) y reemplazar los contratos (por ejemplo el de rabassa morta) con contratos de arrendamiento a corto plazo o de aparcería (Ferrer y Moreno, 2018; Moreno, 2018), para aumentar su parte de la cosecha y su renta de la tierra, aprovechando las condiciones del mercado. O simplemente para desnaturalizar el contrato (Vilar, 1962; Serra, 1989, 2003; Ferrer y Moreno, 2018) por diferentes medios, antes de su erradicación, como ocurrió con los foros dados por instituciones eclesiásticas en Asturias ${ }^{34}$, en un contexto de aumento de precios y rentas.

Pero no siempre fue la renta la que motivó a los dueños directos. Hubo coyunturas menos boyantes, en las que esos poseedores también insistieron en modificar los contratos enfitéuticos. Por ejemplo, para suprimir su perpetuidad (o cuasi perpetuidad) y darles duración en el siglo. Fue, entre otras, una práctica de la reacción señorial eclesiástica contra la autonomía de posesión de los enfiteutas ${ }^{35}$, es decir contra el "oscurecimiento de la posesión”, como decían entonces, que era un serio desafío al dominio directo. Luego, suprimida la perpetuidad de los contratos, el dominio directo quiso acabar con las "astucias" de labradores y campesinos que "vivían" más tiempo que el número de vidas de los contratos, con una sospechosa longevidad cuyo fin era hacer perenne su posesión de las tierras. También por esas razones (y no sólo por rentas) los dueños directos buscaron reemplazar los contratos enfitéuticos con contratos de arrendamiento a corto plazo ${ }^{36}$. Uno de los principales teatros europeos de esa reacción fue la España septentrional y occidental (norte de León, Asturias y sobre todo Galicia). ${ }^{37}$

Pero se debe citar asimismo el tránsito inverso, es decir, desde el arrendamiento a corto plazo al contrato enfitéutico. Fueron la lucha y la presión de los antiguos enfiteutas, transformados contra su voluntad e interés en locatarios de corto plazo (de los bienes que antes poseyeran), los motores de ese retorno. Aunque este también pudo ser provocado por el contexto económico (evolución de precios y tipos de interés) o demográfico (demanda de tierras). Por ejemplo, las enfiteusis urbanas en Milán durante el siglo XVII, estimuladas por la deflación (durante los años 1630), mientras que la inflación previa había favorecido la expansión del arrendamiento a corto plazo (Barbot, 2018) ${ }^{38}$. El dueño directo aprovechó el período expansivo para aumentar sus ingresos (o protegerse de la erosión de sus rentas), y luego, en un contexto de morosidad, prefirió el cobro regular de un canon enfitéutico estable para proteger su poder adquisitivo. Pasó lo mismo, dos siglos más tarde, con instituciones clericales del siglo XIX latinoamericano. Sin escrúpulos ni reservas doctrinarias o morales, esas entidades imponían alternativamente, para sus activos urbanos, según la coyuntura de precios, contratos enfitéuticos o de locación a corto plazo, con preferencia por estos últimos en fases de inflación (o hiperinflación) e incluyendo en los contratos cláusulas de mantenimiento y mejora de los activos, que se incorporaban al patrimonio del dueño sin compensación alguna para el arrendatario (Luna, 1999, 2017b).

En ese ir y venir, de enfiteusis a arrendamiento a corto plazo, vemos primero la voluntad de los dueños directos de defender sus intereses inmediatos (su renta), con la explotación económica y el mantenimiento de 
sus bienes, pero también su vocación de conservar la posesión directa, o volverla absoluta, unificada, "perfecta" avant la lettre, casi como precursores de cierto ideal liberal. Pero notamos, en segundo lugar, su adaptación a la coyuntura delante de los contratos (incluso la enfiteusis), a pesar del riesgo de desposesión.

Tanto la opción por el contrato enfitéutico como la imposición del arrendamiento a corto plazo operaban en un cuadro conflictivo o se resolvían mediante la negociación, según la correlación de fuerzas y el contexto. Los itinerarios previstos con anticipación (por las leyes, las costumbres y tradiciones, o por los mismos analistas) no siempre se cumplían, ni mucho menos. Vale que recordemos que el ciclo de vida, variable individual o colectiva, es decir el avance de la edad de los protagonistas y la etapa vital en que se hallaban, desempeñaron un papel decisivo (Boudjaaba, 2018). Algunas familias, según los contextos y medios, pudieron optar por hacerse enfiteutas, apostando por la garantía y la seguridad de tenencia de sus parcelas y su explotación económica. Pero se requieren nuevas investigaciones al respecto.

\subsection{La preferencia por la enfiteusis}

¿Por qué ha ocurrido que los enfiteutas han preferido muy a menudo la posesión desdoblada, desdeñando redimir los censos enfitéuticos, o sea comprarlos, cuando la ocasión llegaba? ¿Por qué han desestimado la opción de volverse íntegros propietarios, uniendo el dominio útil que poseían al dominio directo, en el sentido liberal? Haciendo eco a trabajos anteriores (Peset, 1982), estudios recientes han enfocado la preferencia de los enfiteutas o censatarios por el contrato enfitéutico frente a la plena posesión del bien, el que gracias a su compra habría quedado "liberado" de obligaciones y servidumbres, transformado en mercancía y recurso económico. Según señalan, sólo algunos no poseedores o apenas poseedores han dado el salto a propietarios, cuando tal vez se esperaba un entusiasmo propietal similar, por ejemplo, al observado antes de acceder a la posesión útil.

Podríamos preguntarnos, empero, si no estamos ante una decisión perfectamente coherente y lógica, cuya comprensión aparece cuando nos adentramos en su racionalidad. Recordemos, para situar la problemática, que si los enfiteutas habían accedido al dominio útil de la tierra, también había ocurrido que ellos mismos desdoblaran el dominio, al subestablecer a otros rurales (no siempre parientes); lo que quiere decir que esos enfiteutas habían practicado una subenfiteusis. Es más: esa forma de subestablecimiento se reprodujo varias veces, lo que dio lugar a una singular cadena enfitéutica ${ }^{39}$, contra el mandato de los dueños directos iniciales y los contratos originales. La evolución de la práctica enfitéutica fue así extensiva e intensiva.

Fuera de los casos conocidos, especialmente en la península ibérica, la investigación reciente ha puesto de relieve otros espacios de emulación enfitéutica, por decirlo así. Por ejemplo, las islas Cícladas de Grecia (Zei, 2018), en los siglos XVII y XVIII. La enfiteusis no sólo fue una práctica contractual que favoreció el ascenso social de un grupo de viñateros como clases dominantes, o "nuevos ricos", sino que se volvió una reivindicación de los insulares autóctonos contra los señores venecianos implantados en las islas. Hubo un grupo de rurales que quiso intensificar la enfiteusis a su favor, como los viñateros. Algo similar ocurría al otro lado del Atlántico, en el siglo XVII, en Córdoba, Veracruz, Nueva España (Naveda, 2008; Widmer, 2009; García, 2018). La misma intensividad enfitéutica resalta en otros trabajos, por ejemplo en la ruralidad mallorquina (Morey y Jover, 2018). Allí, los contratos enfitéuticos fueron importados por los "conquistadores" catalanes de la isla, desde el siglo XIII; la oligarquía terrateniente se formó gracias al fideicomiso (una forma particular de mayorazgo). Al cabo de varios períodos, esos poseedores efectuaron cesiones enfitéuticas del dominio útil, dotando a campesinos y sus familias, los que también practicaron la subenfiteusis. A veces fueron razones financieras las que movieron a la oligarquía hacia la enfiteusis, otras fue su voluntad de "romper" nuevas tierras, a cambio de un canon enfitéutico. Luego, a mediados del siglo XIX, los dueños directos se vieron obligados a fraccionar sus mayorazgos (la ley proponía su disolución) y a cederlos en enfiteusis, para conservar por lo menos su dominio directo de las tierras. 
Tanto para el caso mallorquín como para el de Gerona (Congost, Gifre y Saguer, 2018), la evolución extensiva e intensiva de la enfiteusis sentó una pauta en sus respectivas historias rurales, moderna y contemporánea. Ese contrato, según las investigaciones, representó una baza para la expansión agrícola. Los estudios gerundenses insisten en tres consideraciones importantes. Es útil señalarlas porque van a contracorriente de los a priori sobre el desdoblamiento de la posesión y sus repercusiones productivas (presuntamente negativas). En primer lugar, el hecho de que la enfiteusis no sólo permitió el enriquecimiento de los dueños directos sino también la participación en la renta de grupos sociales distintos de las aristocracias terratenientes, como por ejemplo los campesinos no poseedores. En segundo lugar, el hecho de que la correlación de fuerzas creada por los campesinos gerundenses y ampurdaneses fue el factor principal para que prosiguiera la cesión enfitéutica impuesta a los dueños directos (o cuasi-directos), a pesar de coyunturas adversas que hubieran podido frenar el proceso. Pero además, en tercer lugar, gracias a esa correlación de fuerzas favorable, el contrato enfitéutico de rabassa morta (o sea el derecho de cultivar la viña en una parcela mientras su raíz siguiera viva) se volvió en el campo gerundense un derecho perpetuo del dominio útil sobre la tierra donde la viña estaba plantada, casi la posesión plena, mientras que en la Cataluña central ese contrato, con otra correlación de fuerzas, se volvió aparcería.

En ese contexto favorable a los dueños útiles (y los campesinos) por la práctica enfitéutica puede explicarse la falta de entusiasmo de los enfiteutas ante las denominadas leyes liberales del siglo XIX (Congost, Gifre y Saguer, 2018), que querían que estos (dentro de la desamortización española) redimiesen el capital de las enfiteusis, para volverse poseedores de plena posesión, o sea dueños absolutos del bien con dominios reunificados, individuales y perfectos. Es decir que esos enfiteutas podían preguntarse a sí mismos: ¿por qué "comprar" una posesión que, en los hechos, ya era práctica y efectiva pertenencia plena?

Ahora bien, estamos de hecho ante una reacción más generalizada de lo que puede pensarse. Esos enfiteutas catalanes ¿no estaban adoptando el mismo comportamiento que los campesinos franceses, antes, durante y después de la Révolution (Béaur, 2000)? ¿No había sido desde el siglo XVII (e incluso antes) cuando los rurales galos ya se consideraban como poseedores plenos de las tenencias de tierra que habían recibido bajo diversas formas de desdoblamiento de la posesión o contratos enfitéuticos o paraenfitéuticos (Béaur, Congost, Luna, 2018)? O como lo decían los defensores de los foreros y el bloque social galaico-asturiano-leonés opuesto a despojos, desalojos y expulsiones, perpetrados por los dueños directos durante las décadas centrales del siglo XVIII, ¿ya no habían "pagado" suficientemente, ellos y sus antepasados, a los señores laicos y eclesiásticos, por las tierras que trabajaban para mantener a sus familias? ¿No eran también las razones de los enfiteutas valencianos en los establiments del antiguo Reino de Valencia, durante el siglo XIX, al transformar su posesión útil en posesión plena, extinguiendo las anteriores enfiteusis (Gil, 1998)? ¿O en Tenerife, desde fines del siglo XIX hasta el siglo XX (Rodríguez, 2008)?

Sin embargo, no todo se reduce a la cuasi posesión plena de los enfiteutas para explicar su poco entusiasmo por la reunión de dominios y la "perfección" de la posesión. Pudo haber razones que, en su momento, respondieron a la naturaleza misma del proceso de extinción de las manos muertas o los vínculos que ligaban la posesión de tierras y patrimonios. Es lo que se desprende de los análisis de la desamortización del siglo XIX y la fiscalidad, por ejemplo, para la redención de los foros gallegos ${ }^{40}$ (Vallejo, 1992, 2001). Los estudios dicen que la desamortización española del siglo XIX se apoderó de las rentas y el dominio directo, para venderlos o revenderlos a poseedores enriquecidos y no a los censatarios o enfiteutas. Ello tuvo como resultado una transferencia de las formas antiguas de posesión (o las rentas de los capitales) desde el Antiguo Régimen a la sociedad "moderna", liberal, sin cambio substancial. Fue una desamortización con objetivos fiscales, que consolidó los antiguos derechos de posesión, o los volvió “nuevos”, en un período de incertidumbre.

Es decir, resumiendo, la desamortización española no se hizo a favor de los censatarios de los principales o capitales impuestos y desamortizados, o de los enfiteutas, a pesar de toda la retórica sobre los "nuevos propietarios" y el aumento de "ciudadanos". Lo mismo ocurrió en el proceso equivalente en Milán (Barbot, 2018), con la ley de 1864 que abría hipotéticamente la posibilidad de que los enfiteutas livellari pudiesen 
redimir su posesión útil, unificando dominios y volviéndose propietarios "perfectos". Muy pocos candidatos quisieron aprovechar la ocasión, lo que interroga sobre la voluntad de los livellari milaneses de volverse propietarios plenos. Pero ello nos invita, asimismo, a reflexionar sobre los medios necesarios para sufragar el costo de volverse propietarios y los mecanismos disponibles para lograrlo. ${ }^{41}$

En teoría, desde la mirada del observador actual, las motivaciones para volverse propietario de posesión plena pueden parecer obvias (casi naturales). La seguridad de posesión y el estímulo que se imputa al hecho de trabajar sobre algo que se posee y que redundará en beneficio propio pueden parecer razones irrebatibles para volverse propietario pleno. Sin embargo, al acercarse a los detalles del asunto (allí "donde se esconde el diablo"), se impone plantearse la cuestión del costo efectivo de la propiedad plena, tal como se fijó en cada lugar y coyuntura, por el denominado Estado "liberal" y los grupos sociales que asumieron su control. O cuando las relaciones socioeconómicas (o el mercado), con independencia relativa de la ley o del Estado, así lo determinaron. Sin olvidar que poder sociopolítico, estructura estatal, ley, acción del mercado, poder socioeconómico y correlación de fuerzas son factores que interactúan permanentemente. Pero ¿de qué estamos hablando concretamente?

Hablamos de un costo compuesto de varios elementos. En primer lugar, el precio fijado de la redención de las enfiteusis y la reunificación de dominios. En segundo lugar, los costos colaterales para pagar la mencionada plena posesión: acceso al crédito e intereses, condiciones de pago, plazos, gastos notariales, entre otros. Pero además, en tercer lugar, hay que considerar la lógica de la redención propuesta. ¿Podíamos esperar que los censuatarios o enfiteutas se entusiasmaran con un trámite basado en la capitalización (compra del capital representativo del bien) a beneficio de los dueños directos, o incluso del Estado? Porque era eso, capitalizar a los dueños directos (o al Estado) con un traspaso de capital dinero desde la posesión útil (lo más seguro: con el endeudamiento de enfiteutas o censuatarios).

Es decir que estábamos ante una lógica y un mecanismo que eliminaban cualquier otra forma de capitalización posible, por ejemplo, la del trabajo humano vertido por los enfiteutas (tal vez por generaciones), cristalizado en la posesión útil. Esa lógica de capitalización, su costo en intereses (o sea el precio del capital) y el perfil de sus beneficiarios podían naturalmente "desanimar" a los enfiteutas de volverse propietarios plenos. Los enfiteutas o censatarios de entonces se planteaban, seguramente, el mismo problema que aquí estamos formulando.

Y ello aunque ese costo efectivo (o costo propietal), es decir, el acceso a la plena posesión, también incluyera, por defecto, los costes de oportunidad derivados del hecho de carecer de la mencionada plena propiedad (y que no siempre pueden ser contabilizados): la posibilidad de hipotecar un bien de propiedad plena, el acceso al mercado de crédito, las ventajas del registro del bien, entre otros. Sin evocar la cuestión del acceso a la ciudadanía plena, en el cuadro de sistemas de voto censitario, vigentes durante el siglo XIX. La complejidad de todo ello requiere estudios precisos para su mejor comprensión.

\section{5. ¿Será la enfiteusis factor de conflictividad?}

Con frecuencia se ha dicho que las prácticas enfitéuticas fueron fuentes de conflicto, pleitos, reclamos sin fin, inestabilidad, perturbación para la compraventa de tierras; o simplemente, factor de parálisis del mercado de bienes raíces (Rosenthal, 1992). Se ha asegurado que la enfiteusis provocaba el estancamiento del mercado raíz, al inducir la inseguridad de los derechos de posesión y la inhibición de las inversiones, por los conflictos que presuntamente conllevaba y la falta de dominios unificados, en su forma propietal. La tierra de posesión desdoblada no habría alcanzado la forma superior de mercancía negociable al no estar individualizada, ni liberada de servidumbres externas. El que hubiese más de un poseedor se consideraba factor de incertidumbre para las decisiones. ${ }^{42}$ Vale precisar que no fueron solamente los partidarios de la teoría neoinstitucionalista los defensores de tal interpretación. 
Investigaciones recientes han examinado los conflictos sociales en los denominados espacios enfitéuticos, sin imputarlos necesariamente al tipo de contrato. Por ejemplo, a fines del siglo XVII y comienzos del XVIII, cuando la oligarquía terrateniente mallorquina efectuó cesiones enfitéuticas, empujada por deudas, con una correlación de fuerzas desfavorable (Morey y Jover, 2018). Con la voluntad de aumentar la presión sobre los debilitados dueños directos, los enfiteutas intentaron ir más allá de la concesión obtenida: trataron de reocupar tierras comunales que habían sido usurpadas por la nobleza (y antepasados), y extendieron su sed recuperadora a tierras que nunca habían formado parte de las comunales, que ocuparon, "rompieron" y cultivaron de forma ilegal. Se negaron a pagar el canon enfitéutico y extrajeron leña y frutos del bosque, además de actos similares poco relacionados con el contrato enfitéutico. Ocurría lo mismo en otros momentos, en respuesta a decisiones de los dueños directos: alza de precio de los productos vendidos a los campesinos o de servicios prestados, baja de las remuneraciones, o cuando los directos se negaban a la cesión enfitéutica. Casos similares han existido en lugares y coyunturas comparables (Chittolini, 2018; Zei, 2018), con conflictos diversos, incluso entre enfiteutas y campesinos parcialmente asalariados. ${ }^{43}$

Ahora bien, podríamos preguntarnos si fue la naturaleza enfitéutica del contrato la que indujo la confrontación entre sus protagonistas. Evidentemente, se necesitarían más estudios para acercarse al problema, ya que también se presentaron (y presentan) conflictos bajo otro tipo de contratos (arrendamiento a corto plazo o aparcería), incluso en el contexto de la unificación de los dominios de posesión. Por ello, se podría formular una hipótesis alternativa: si en vez de hacer pesar la responsabilidad de los conflictos sobre la enfiteusis, no tendríamos que poner de relieve como factor el cuestionamiento de la legalidad de los contratos (parcial o total), ya sea por el dominio directo, ya sea por el útil. El acto ilegal, fundado en una correlación de fuerzas en que se modificaban los anteriores equilibrios sociales, podía ser el primer paso en busca de una nueva legalidad; una búsqueda tanto del dominio directo como del útil. ${ }^{44}$ Como en otros contratos, la correlación de fuerzas (nutrida por el descontento) podía cuestionar el contrato por razones ligadas más al contexto, a las perspectivas y desventajas potenciales, a la inseguridad o la injusticia que se consideraba padecer, que a las condiciones del contrato. ¿Se trataba, en un caso, de la consolidación de grupos emergentes? ¿Se trataba, en otro caso, de la reacción de defensa de los más débiles? ¿Economía política versus economía moral (Gauthier y Ikni, 2019)?

Sin embargo, no debemos pasar por alto que en la mayoría de los casos estudiados fue sobre todo el dominio directo el que tomó la iniciativa de la ruptura de la legalidad, con el fin de instaurar otra; a veces para retornar a una forma anterior, otras para imponer un contrato distinto a los vigentes, por la vía práctica, la acción y la intervención directas. Ya sea porque trataba de preservar o aumentar la renta de la tierra, al presentar la coyuntura comercial y económica posibilidades favorables; ya sea porque se temían nuevos desposeimientos que la memoria institucional no había olvidado. Si se apuntaba al contrato enfitéutico y su erradicación, era probable que fuese más que todo porque era la forma contractual del momento, con un equilibrio de intereses que se pretendía modificar. Por ello, la idea de una enfiteusis como factor de conflictos equivaldría a tomar el pretexto como causa. Pero es obvio que se requieren más trabajos al respecto, que no descarten ninguna hipótesis.

\section{6. ¿Será la enfiteusis factor de retraso económico?}

Aquí se nos replantea el vínculo entre desdoblamiento de la posesión y crecimiento económico. El solo hecho de enunciar la cuestión es de por sí una interrogación o desafío con respecto al exclusivo enfoque neoinstitucionalista, para el cual, por lo general, no cabe crecimiento sin la victoria institucional previa de los derechos de propiedad, absolutos, individualizados, unificados y sancionados por la ley y el Estado, o sea "perfeccionados" (North, 1996). En recientes trabajos, contrariamente a ese requerimiento, parecen detectarse casos y posibilidades de relación positiva entre enfiteusis y progreso económico (Congost y Luna, 
2018). Pero también se observan otros en los que se asocia el crecimiento agrícola (y económico) a la plena posesión y el arrendamiento a corto plazo.

Fuera de los estudios ya conocidos, análisis recientes han demostrado que en contextos de falta de capitales (o escasez monetaria), la práctica enfitéutica ha permitido la expansión productiva, al incorporar trabajo y nuevas tierras a la explotación económica (Boudjaaba, 2018; Zei, $2018^{45}$; Morey y Jover, 2018). Al mismo tiempo, otros trabajos registran el aumento productivo y la consolidación de la demografía, gracias a la plena posesión de la tierra y su fraccionamiento mediante contratos de arrendamiento a corto plazo (Chittolini, 2018). Esto podría simplemente significar que un mismo resultado puede ser obtenido mediante diversos mecanismos y que no habría regla, ni única ni absoluta, para alcanzarlos.

Por otro lado, dentro del mismo cuadro problemático, podríamos preguntarnos si el mantenimiento de la práctica enfitéutica fue un obstáculo para el aumento de las rentas de los dueños directos, civiles o eclesiásticos. ¿Habrán sido los contratos enfitéuticos una barrera demasiado elevada para el aumento de su renta de la tierra? Nos harían falta estudios precisos para pronunciarnos, pero algunas investigaciones ya nos dan algunos índices. Por ejemplo, los monasterios gallegos registraron un mantenimiento y hasta un aumento de su renta cerealera, entre la segunda mitad del siglo XVIII y los primeros años del siglo XIX, es decir cuando se mantenía vigente la Pragmática de 1763 (ver nota 40) que prolongaba indefinidamente los contratos de foro y prohibía las expulsiones (Saavedra, 2018). Y simultáneamente, en la misma área de vigencia de la disposición de 1763, el monasterio asturiano de San Pelayo, que había logrado imponer el arrendamiento a corto plazo en reemplazo de los foros enfitéuticos, también registraba el alza significativa de sus rentas durante la segunda mitad del siglo XVIII y comienzos del siglo XIX (Luna, 2018).

Con ello tendríamos otra vez, ahora para el aumento de rentas, un mismo resultado, con dos tipos de mecanismos: el uno gracias al foro enfitéutico, el otro gracias a la plena posesión y el arrendamiento a corto plazo. Pero sería sólo un aspecto de la cuestión, si no tomáramos en cuenta que tanto los monasterios y conventos gallegos como los asturianos, respectivamente dueños directos, o cuasi propietarios de posesión plena, participaban activamente en el comercio de granos y cereales, utilizando los mecanismos de precios y las equivalencias entre cereales. Es decir que sabían exigir el pago de la renta en los cereales más beneficiosos, según la perspectiva de precios, imponiendo su correlación de fuerzas. ${ }^{46}$

Con ello permanece la pregunta de si, a pesar de los resultados positivos, la práctica enfitéutica no hizo más complicado el aumento de la renta y si el arrendamiento a corto plazo, allí donde se impuso, no lo facilitó. Al final de cuentas, sólo contamos con pocos índices y nos queda abierto un campo de investigación sobre la relación entre enfiteusis, arrendamiento a corto plazo, inversión y producción, coyuntura económica y comercial, crecimiento de la renta de la tierra, etc. Con la condición de no tomar la enfiteusis como el duende maléfico de los bosques medievales y sin caer en el extremo opuesto que sería considerarla como la panacea (rural y/o urbana) para lograr el equilibrio y la reproducción sociales armónicos.

Una última precisión sobre los casos ibéricos estudiados. Aunque la perspectiva económica o sus resultados no debieran ser los únicos que se tomen en cuenta para explicar la opción de los no poseedores por la enfiteusis, es importante recordar que ha habido espacios enfitéuticos en los que se produjo una favorable evolución demográfica ( sin establecer un vínculo de causa/efecto entre ambas), con resultados débiles desde la óptica del crecimiento económico agrícola (salvo en determinados momentos). Esto nos llevaría a confirmar que si las prácticas enfitéuticas pudieron desempeñar un papel motor para el crecimiento económico, al aumentar el trabajo aplicado a la tierra, para cultivos nuevos o antiguos, tienen que considerarse otros factores para explicar el porqué de dicho proceso virtuoso (Congost, 1989; Béaur, Congost y Luna, 2018). Es decir que, en el fondo, la cuestión planteada sigue siendo la de las condiciones requeridas para que la práctica enfitéutica pueda favorecer el crecimiento productivo y si hay límites inherentes al desdoblamiento de la posesión que pueden hacer que el signo positivo se vuelva negativo, en un momento determinado. 


\section{A MODO DE CONCLUSIÓN}

La problemática que hemos tratado de examinar se sitúa en el cruce de tres asuntos fundamentales para la historia del mundo rural, válidos también para el espacio hispanoamericano. Estamos hablando, en primer lugar, de los derechos de posesión sobre la tierra y las riquezas naturales, en segundo lugar de la organización del trabajo agrícola y la repartición de sus frutos y, en tercer lugar, de la transición propietal desde el Antiguo Régimen hacia el mundo actual, es decir desde la posesión hasta la propiedad.

La enfiteusis y su práctica contractual de desdoblamiento de dominios ofrecen un terreno privilegiado de trabajo histórico y reflexión, en particular en nuestros espacios hispanoamericanos, tanto cuando existen, de manera abierta o encubierta, en el cuadro de las formas contractuales prácticas, como por su ausencia. Enfocar la enfiteusis y la posesión desdoblada de la tierra y las riquezas naturales es también, como en el caso europeo, entrar de lleno en las relaciones de clases, en el campo y la ciudad hispanoamericanos.

Por ello, las discusiones a las que invita el avance de la investigación reciente sobre el asunto no son (ni mucho menos) exclusivamente discusiones europeas o de países desarrollados ("ajenas a las nuestras"), tanto más cuanto que el contrato enfitéutico reaparece hoy en día, en los espacios y situaciones menos esperados, en diversos puntos del planeta, reanudando su evolución con interrogaciones antiguas que el historiador debería presentar a sus contemporáneos, casi como una tarea ciudadana, como una función inherente a su oficio.

Sobre todo cuando sabemos que allí donde en el pasado se pudo desarrollar, la enfiteusis ha sido ignorada o desdeñada durante muchos años, al ser considerada como un factor negativo (y hasta pernicioso) para el crecimiento agrícola y el funcionamiento económico, a secas. Una condena que han hecho suya algunos ideólogos contemporáneos, partidarios de la propiedad plena y absoluta (privada por añadidura), opuestos a todo lo que pueda significar cuestionarla, tanto en el presente como en el pasado.

\section{REFERENCIAS}

Anes, G. (1995). La Ley Agraria. Madrid: Alianza Editorial.

Ardit, M. (2012). Confiscación, repoblación y conflictos sociales en el campo valenciano después de la expulsión de los moriscos. En S. de Dios, J. Infante, R. Robledo y E. Torijano. Historia de la propiedad. La expropiación (pp. 83-98). Salamanca: Ediciones de la Universidad de Salamanca.

Argyrou, E. (2003). Les baux ruraux dans une île ionienne. L'exemple de Leucade au XVIII siècle. En G. Béaur, M. Arnoux y A. Varet-Vitu. Exploiter la terre. Les contrats agraires, de l'Antiquité à nos jours (pp.155-165). París: Association Histoire et Société Rurales.

Assadourian, C.S. (1982). El sistema de la Economia Colonial. Mercado interno, regiones y espacio económico. Lima: Instituto de Estudios Peruanos.

Assadourian, C.S. (1991). Estructuras económicas coloniales: El sistema de las haciendas. En C. Assadourian y A. Martínez. Tlaxcala, una historia compartida, siglos XVII-XVIII (pp. 11-90). Tlaxcala: Consejo Nacional para la Cultura y las Artes. Vol. 10.

Assadourian, C.S. (1994). Transiciones hacia el Sistema Colonial Andino. Lima y México: El Colegio de MéxicoInstituto de Estudios Peruanos.

Avila, A. (2014). El Ayuntamiento de Antigua Guatemala y la administración de sus ejidos. De la enfiteusis a la propiedad privada (Tesis doctoral). El Colegio de México: Centro de Estudios Históricos, México.

Aymard, M. (2011). Conclusion Colloque de Gérone, tapuscript.

Bagú, S. (1966). El plan económico del Grupo Rivadaviano, 1811-1827: Su sentido y sus contradicciones; sus proyecciones sociales; sus enemigos. Rosario: Universidad Nacional del Litoral, Instituto de Investigaciones Históricas.

Barbot, M. (2018). What the Dominia Could Do: Enfiteusis and Other Forms of Divided Property Rights in Lombardy from the Fourteenth to the Twentieth Centuries. En R. Congost y P.F. Luna (Eds.), Agrarian Change and Imperfect Property: Emphyteusis in Europe (16th to 19th centuries) (pp.53-73). Turnhout: Brepols. 
Barbot, M., Lorenzetti, L. y Morelli, L. (Eds.) (2012). Property Rights and theirs Violations. Expropriations and Confiscations, 16th - 20th centuries. Berna: Peter Lang.

Barcos, M. F. (2013). Los derechos de propiedad ejidal en el contexto desamortizador iberoamericano. América Latina en la Historia Económica, 20, 1, 98-123.

Béaur, G. (2000). Histoire agraire de la France au XVIII siècle. París: Editions Sedes.

Béaur, G. (2003). Contrats d'exploitation et système de contrats dans la France d'Ancien Régime. En G. Béaur, M. Arnoux y A. Varet-Vitu. Exploiter la terre. Les contrats agraires, de l'Antiquité à nos jours (pp. 35-44). París: Association Histoire et Société Rurales.

Béaur, G. (2018). The Many Faces of Emphyteusis in France: An Overview with a Case Study from the Meaux Region (1600-1800). En R. Congost y P. F. Luna (Eds.), Agrarian Change and Imperfect Property: Emphyteusis in Europe (16th to 19th centuries) (pp.75-96). Turnhout: Brepols.

Béaur, G., Arnoux, M. y Varet-Vitu A. (2003). Exploiter la terre. Les contrats agraires, de l'Antiquité à nos jours. París: Association Histoire et Société Rurales.

Béaur, G., Schofield, Ph., Chevet, J. M. y Pérez-Picazo, M. (Eds.) (2013), Property Rights. Land Markets and Economic Growth in the European Countryside (Thirteenth-Twentieth Centuries). Turnhout: Brepols.

Béaur, G. y Chevet, J. M. (2017). Droits de propriété et croissance. L'émergence de la propriété «parfaite» et l'ouverture du marché foncier, moteurs de la croissance agricole? Histoire et Sociétés Rurales, 48, 2, 49-92.

Biagioli, G. (2003). Les contrats dans l'historiographie italienne de la période contemporaine. En G. Béaur, M. Arnoux y A. Varet-Vitu, Exploiter la terre. Les contrats agraires, de l'Antiquité à nos jours (pp. 63-84). París: Association Histoire et Société Rurales.

Boehler, J-M. (2018). Erblehn and Hoflehn in Germanic Lands: Disguised Forms of Ownership? The Alsatian Countryside in the Seventeenth and Eighteenth Centuries. En R. Congost y P.F. Luna (Eds.), Agrarian Change and Imperfect Property: Emphyteusis in Europe (16th to 19th centuries) (pp. 97-112). Turnhout: Brepols.

Boudjaaba, F. (2018). Emphyteusis in Practice in Eigthteenth Century Normandy: Why Choose the Fieffe. En R. Congost y P. F. Luna (Eds.), Agrarian Change and Imperfect Property: Emphyteusis in Europe (16th to 19th centuries) (pp. 113-131). Turnhout: Brepols.

Camara, B. (2018). The Colonia Contract: Ambiguity between Sharecropping, Fixed Rent and Emphyteusis. En R. Congost y P. F. Luna (Eds.), Agrarian Change and Imperfect Property: Emphyteusis in Europe (16th to 19th centuries) (pp. 263-285). Turnhout: Brepols.

Canales, G. y Muñoz, R. (2001). Los jesuitas y la Hacienda La Marquesa; Una iniciativa colonizadora en el secano litoral del Bajo Segura (1694-1767). Alquibla, 7, 19-55.

Camara, B. (2002). La Hacienda La Marquesa: De la expulsión de los Jesuitas a la venta del predio por la Junta de Temporalidades (1767-1786). El freno a una acción colonizadora al cambiar la enfiteusis por el arrendamiento como forma de explotación de la tierra. Alquibla, 8, 93-144.

Charle, C., (1980). Entretiens avec Ernest Labrousse, Actes de la Recherche en Sciences Sociales, 32-33, 111-127.

Cheneval, F. y De Soto, H. (2006). Realizing Property Rights. Zurich: Rüffer and Rub.

Clavero, B. (1980). Foros y rabassas; Los censos agrarios ante la revolución española. Agricultura y sociedad, 16, 27-69.

Clavero, B. (1981). Foros y rabassas; Los censos agrarios ante la revolución española (segunda parte), Agricultura y sociedad, 18, 65-100.

Clavero, B. (1986). Enfiteusis, ¿Qué hay en un nombre? Anuario de historia del derecho español, 56, 467-520.

Cobarrubias, S., (1611). Tesoro de la lengua castellana, o española, Madrid: Imp. Sánchez.

Colmenares, G. (1969). Las haciendas de jesuitas en el Nuevo Reino de Granada. Bogotá: Universidad Nacional de Colombia.

Colmenares, G. (1974). Censos y capellanías: formas de crédito en una economía agrícola, Cuadernos Colombianos, 2, 123-143.

Colmenares, G., (1975). Cali: Terratenientes, mineros y comerciantes. Cali: Universidad del Valle. 
Comby, J., (1990). «L'impossible propriété absolue », en Association des Etudes foncières, Un droit inviolable et sacre. París: ADEF, 9-20.

Congost, R. (1989). Presión demográfica, relaciones de clase y producción agrícola en la región de Gerona (1768-1862). Agricultura y Sociedad, 50, 155-186.

Congost, R. (2000). Els darrers Senyors de Cervià de Ter. Investigaciones sobre el caracter mutant de la propietat (segles $X V I I-X X)$. Girona: COG Edicions.

Congost, R. (2003). Property Rights and Historical Analysis: What Rights? What History? Past and Present, 181, 73-106.

Congost, R. (2007). Tierras, Leyes, Historia. Estudios sobre la "gran obra de la propiedad". Barcelona: Crítica.

Congost, R. y R. Santos, (Eds.) (2011). Contexts of Property in Europe. The Social Embeddedness of Property Rights in Land in Historical Perspective. Turnhout: Brepols.

Congost, R., J. Gelman y R. Santos, (Eds.) (2017). Property Rights in Land. Issues in Social, C Economic and Global History. London y New York: Routledge.

Congost, R. y P. F. Luna, (Eds.) (2018). Agrarian Change and Imperfect Property: Emphyteusis in Europe (16th to 19th centuries), Turnhout: Brepols.

Congost, R., Gifre, P. y Saguer, E. (2018). More than just Access to Land: Emphyteusis and the Redefinition of Property Rights in North-East Catalonia (Eighteenth and Nineteenth Centuries). En R. Congost y P. F. Luna (Eds.), Agrarian Change and Imperfect Property: Emphyteusis in Europe (16th to 19th centuries) (pp. 133-154). Turnhout: Brepols.

Cordero, E. (2008). De la propiedad a las propiedades: La evolución de la concepción liberal de la propiedad. Revista de Derecho, XXXI, 493-525.

Cordero, E. y Aldunate, E. (2008). Evolución histórica del concepto de propiedad. Revista de Estudios HistóricoJurídicos, 30, 345-385.

Cárdenas, de, F. (1873). Ensayo sobre la historia de la propiedad territorial en España. Madrid: Imprenta de J. Noguera a cargo de M. Martínez.

Deininger, K. (2003) (Ed.). Land Policies for Growth and Poverty Réduction. Washington: World Bank y Oxford University Press.

Dios, de, S. et al (2012). Historia de la propiedad. La expropiación. Salamanca: Ediciones de la Universidad de Salamanca.

Dios, de, S., J. Infante, R. Robledo y E. Torijano (1999). Historia de la propiedad en España, siglos XVI-XX. Salamanca: Ediciones de la Universidad de Salamanca.

Escobar, A., R. Falcón y M. Sánchez, (2017). La desamortización civil desde perspectivas plurales. México: El Colegio de México/El Colegio de Michoacán/Ciesas.

Fandos, C., (2007). Comment se perpétuer? Systèmes successoraux et transmission patrimoniale dans l'Espagne du XVIII siècle, Histoire et Sociétés Rurales, 27, 1, 37-70.

Fandos, C. (2012). “¿Cómo quitarles esas tierras en un día después de 200 años de posesión?”. Enfiteusis, legislación y práctica en la Quebrada de Humahuaca (Argentina). Bulletin de l'Institut français d'études andines, 41, 2, 209-239.

Fandos, C. (2014). Enfiteutas, propietarios y arrendatarios en el departamento de Humahuaca. Estructura social y distribución de la riqueza, en la década de 1860. Estudios Sociales del NOA, 14, 41-61.

Fandos, C. (2017). La formación histórica de condueñazgos y copropiedades en las regiones de las Huastecas (México) y las tierras altas de Jujuy (Argentina). Revista de Historia Iberoamericana, 10, 2, 49-79.

Fandos, C. y Teruel, A. (2009). Procesos de privatización y desarticulación de tierras indígenas en el norte de Argentina en el siglo XIX. Revista Complutense de Historia de América, 35, 233-255.

Fandos, C. y Moreno, B. (2018). The Origins and Evolution of the Rabassa Morta Contract in Catalonia. En R. Congost y P. F. Luna (Eds.), Agrarian Change and Imperfect Property: Emphyteusis in Europe (16th to 19th centuries) (pp. 155-181). Turnhout: Brepols. 
Farberman, J. (2019). Los avatares de la mancomunión. Propiedad indivisa, armonías y conflictos en las costas del río Dulce, Santiago del Estero, siglos XVIII y XIX. Revista de Indias, LXXIX, 275, 111-142.

Ferreira, C., (1999). El crédito colonial en la provincia de Pamplona, Nueva Granada; U Fandos, C. sos del censo consignativo, Signos Históricos, 1, 1, 59-84.

Ferrer, Ll. (1989). Notas sobre las estructuras agrarias catalanas en el siglo XVIII. En Bernal, A. et al (Eds.), Estructuras Agrarias y reformismo ilustrado en la España del siglo XVIII (pp. 189-212). Madrid: Ministerio de Agricultura, Pesca y Alimentación.

Ferrer, Ll. (2007), Comment se perpétuer? Systèmes successoraux et transmission patrimoniale dans l'Espagne du XVIII siècle, Histoire et Sociétés Rurales, 27, 1, 37-70.

Ferrer, Lly Moreno, B. (2018), The Origins and Evolution of the Rabassa Morta Contract in Catalonia. En R. Congost y P. F. Luna (Eds.), Agrarian Change and Imperfect Property: Emphyteusis in Europe (16th to 19th centuries) (pp. 155-181). Turnhout: Brepols,

Ferreyra, A. (2014). Relaciones sociales en el mundo rural. Córdoba, 1780-1855. Mundo Agrario, 15, 30, http://ww w.mundoagrario.unlp.edu.ar/article/view/MAv15n30a02/6447

García, B. (1992). Jurisdicción y propiedad: Una distinción fundamental en la historia de los pueblos de indios en el México colonial, European Review of Latin American and Caribbean Studies, 53, 47-60.

García, L. (2018). La enfiteusis en el centro de Veracruz: Entre individualismo agrario y expectativas de reforma, 1758-1811. En S. Álvarez, M. Menegus y A. Tortolero (Comps.), Derechos de propiedad y crecimiento económico en la historia agraria: Contribuciones para una perspectiva comparada en América y Europa (pp. 205-228). Santa Marta: Universidad del Magdalena.

Gil, A. (1988). Declive y ocaso de la enfiteusis señorial valenciana. Agricultura y Sociedad, 49, 293-318.

Guégan, I. (2018). Rapport à la terre, conflits et hiérarchies sociales en Basse-Bretagne au 18e siècle (Tesis doctoral), Universidad de Brest, Brest, Francia.

Gauthier, F. e Ikni, G. (Eds.) (2019). La guerre du blé au XVIIIe siècle. La critique populaire de la liberté économique. París: Editions Kimé.

Lemeunier, G (1989). Cens enfitèutic i colotnizació agrícola a Múrcia (1450-1900), primera part. Estudis d'história agrària, 7, 51-76.

Levaggi, A. (1992). Las capellanias en la Argentina. Estudio Histórico-Jurídico. Buenos Aires: Universidad de Buenos Aires.

Levaggi, A., (2012). La enfiteusis en la Argentina (siglos XVII-XX). Estudio histórico-jurídico. Buenos Aires: Ediciones Universidad del Salvador.

López, C. (2013). Entre sermones y cuentas. Actividad misionera y económica de los jesuitas en la Gobernación de Tucumán, Revista de la Junta de Estudios Históricos de Tucumán, 13, 33-50.

Luna, P. F. (1999). “Conventos, monasterios y propiedad urbana en Lima, siglo XIX: el caso de la Buenamuerte”. Actas del XII Congresso Internacional AHILA (pp.547-561). Porto, Portugal, Universidade do Porto, V.

Luna, P. F. (2006). La Reforma de la sociedad y la defensa de los derechos del propietario, según G.M. de Jovellanos, a finales del Antiguo Régimen. Oviedo: RIDEA.

Luna, P. F. (2012). La propiedad y el trabajo en la reflexión de Jovellanos. Revista Asturiana de Economía, 45, 75-95.

Luna, P. F., (2016). Le landgrabbing: une contre-réforme agraire?. En J. P. Jessenne, P. F. Luna y N. Vivier, Les réformes et lois agraires dans le monde (16e-21e siècle), dossier de la Revue d'Histoire moderne et contemporaine,64, 4/4bis: 157-182.

Luna, P. F., (2017a). Terre et droit dans le Nord-Ouest de l'Espagne: Entre le manifeste légal et la raison naturelle. En P. F. Luna y N. Mignemi (Dir.), Prédateurs et Résistants. Appropriation et réappropriation de la terre et des ressources naturelles (16e - 20e siècle), París: Ed. Syllepse: 89-117.

Luna, P. F. (2017b). El tránsito de la Buenamuerte por Lima. Auge y declive de una orden religiosa azucarera. Siglos XVIII y XIX. Madrid, Frankfurt: Iberoamericana-Verwuert. 
Luna, P. F. (2018). From Foro to Renting (and back?). Emphyteutic Tenure at the Asturian Monastery of San Pelayo during the Old Regime. En R. Congost y P. Luna (Eds.), Agrarian Change and Imperfect Property: Emphyteusis in Europe (16th to 19th centuries) (pp. 237-262). Turnhout: Brepols.

Luna, P. F. y F. Quiroz (2019). Introducción. En P. F. Luna et F. Quiroz Ch. (Eds.), Haciendas en el Mundo Andino, Siglos XVI-XX. Lima: Institut français d'études andines (Umifre 17) / Fondation M. J. Bustamante de la Fuente, avec le soutien du Centre de recherches historiques CRH (CNRS-EHESS UMR 8558), 11-49.

Macera, P. (1966). Instrucciones para el manejo de las haciendas jesuitas del Perú (ss XVII y XVIII). Lima: Universidad Nacional Mayor de San Marcos.

Macera, P. (1976). Palto, hacendados y yanaconas del algodonal peruano (Documentos 1877-1943). Lima: Universidad Nacional Mayor de San Marcos.

Madrazo, G., (1990). El proceso enfitéutico y las tierras de indios en la Quebrada de Humahuaca (Provincia de Jujuy, República Argentina). Período Nacional, Revista Andes, 1, 89-114.

Marcos, A. (1999). Estructuras de la propiedad en la Epoca Moderna. Evolución y variantes peninsulares. En Dios, de, S., J. Infante, R. Robledo y E. Torijano, Historia de la propiedad en España, siglos XVI-XX. Salamanca: Ediciones de la Universidad de Salamanca, 113-162.

Marcos, A. (2012). Sobre desmembraciones, incorporaciones y ventas de señoríos eclesiásticos y de órdenes militares de Castilla, durante el siglo XVI. En Dios, de, S., J. Infante, R. Robledo y E. Torijano, Historia de la propiedad. La expropiación. Salamanca: Ediciones de la Universidad de Salamanca, 51-81.

Mariluz, J. (1970). La propiedad en el derecho indiano, Revista Chilena de Historia del Derecho, 6, 154-157.

Mariluz, J. (1978). El Régimen de la Tierra en el Derecho Indiano. Buenos Aires: Editorial Perrot.

Marcos, A. (1978). El Régimen de la Tierra en el Derecho Indiano. Buenos Aires: Editorial Perrot.

Mata, S. (2019) (Coord.). Derechos de acceso a la tierra: documento de trabajo $N^{\circ} 1$. Salta: Instituto de Investigación en Ciencias Sociales y Humanidades - Conicet.

Menegus, M. (1992). Indios censualistas. El censo enfitéutico en el Marquesado del Valle, siglo XVIII. Historias, 28, 65-74.

Menegus, M. (2009). La Mixteca Baja. Entre la Reforma y la Revolución. Cacicazgo, territorialidad y gobierno, siglos XVIII y XIX. Oaxaca: Universidad Autónoma "Benito Juárez" de Oaxaca-Universidad Autónoma Metropolitana de México- Congreso del Estado de Oaxaca.

Menegus, M. y M. Peset, (1994). Rey propietario o rey soberano. Historia Mexicana, XLIII: 4, 563-599.

Moreno, B. (2018). La rabassa morta, sus actores y la defensa del carácter enfitéutico, 174-1850. Historia Agraria, 78, $1-30$.

Morey, A. y Jover, G. (2018). From 'Feudal' to 'Common' Emphyteusis in Rural Mallorca, Eighteenth to Twentieth Centuries. En R. Congost y P.F. Luna (Eds.), Agrarian Change and Imperfect Property: Emphyteusis in Europe (16th to 19th centuries) (pp. 183-206). Turnhout: Brepols.

Mumford, J. (2012). Vertical Empire: The General Resettlement of Indians in the Colonial Andes. Durham: Duke University Press.

Naveda, A. (2008). Esclavos negros en las haciendas azucareras de Córdoba, Veracruz, 1690-1830. Xalapa: Universidad de Veracruz.

North, D. (1995). Instituciones, cambio institucional y desempeño económico. México: Fondo de Cultura Económica.

Oñate, T., García, L. y Ternera, F. (2018). Por el Derecho de Enfiteusis: Defensa de una útil desmembración de la propiedad. Revista Boliviana de Derecho, 25, 320-341.

Pérez-Picazo, M. (1989). Cens enfitèutic i colotnizació agrícola a Múrcia (1450-1900), segona part. Estudis d'história agrìia, 7, 77-97.

Peset, M. (1982). Dos ensayos sobre la historia de la propiedad de la tierra. Madrid: Edersa.

Peset, M. (1989). L’emfiteusi al Regne de València. Una anàlisi jurídica. Estudis d'história agrària, 7, 99-126.

Rey Castelao, O. y P. Cowen (2017). Familias en el viejo y el nuevo mundo. La Plata: Universidad de la Plata. 
Rodríguez, L. (2007). El foro galaico: una derivación natural de la enfiteusis greco-romana. Revista de estudios históricojurídicos, XXIX, 357-372.

Rodríguez, J. (2008). La pervivencia parcial del sistema de propiedad feudal en la España contemporánea: La enfiteusis en Tenerife. Hispania Nova, 8, 60-81.

Rosenthal, J. L. (1992). The Fruits of Revolution: Property Rights, Litigation and French Agriculture. Nueva York: Cambridge University Press.

Saavedra, P. (1985). Economía, política y sociedad en Galicia: la provincia de Mondoñedo, 1480-1830. Santiago de Compostela: Xunta de Galicia.

Saavedra, P. (2018). Foros: Land Tenures a Source of Income and Conflict in Early-Modern Galicia. En R. Congost y P.F. Luna (Eds.), Agrarian Change and Imperfect Property: Emphyteusis in Europe (16th to 19th centuries) (pp. 207-235). Turnhout: Brepols.

Sánchez, F., Fazio, A. y López, M. (2007). Conflictos de tierras, derechos de propiedad y el surgimiento de la economía exportadora en el siglo XIX en Colombia. Bogotá: Universidad de los Andes.

Santos, R. y J.V. Serrao, (2013). Property rights, social appropriations and economic outcomes: Agrarian contracts in Southern Portugal in the late eighteenth century". En G. Béaur, Ph. Schofield, J. M. Chevet y M. Pérez-Picazo (Eds.), Property Rights. Land Markets and Economic Growth in the European Countryside (Thirteenth-Twentieth Centuries) (pp. 475-494). Turnhout: Brepols.

Sanz A. (2004). Aproximación documental a la economía clariana aragonesa: Los documentos del Archivo Histórico Nacional. En F. Campos La clausura femenina en España: Actas del simposium, 1-4/09/2004. San Lorenzo de El Escorial: Real Centro Universitario Escorial - María Cristina, vol. 2, 1185-1212.

Sanz, M. (1998). Contratos agrarios del Cabildo Catedral de Oviedo a comienzos del siglo XIV. Estudio diplomático. Historia, Instituciones, Documentos, 25, 625-637.

Serra, E. (1989). Notes sobre els orígens i l'evolució de l'emfiteusi a Catalunya. Estudis d'história agrària, 7, 127-138.

Serra, E. (2003). Les contrats agraires dans la Catalogne moderne (XVIe-XVIIe siècles). En G. Béaur, M. Arnoux y A. Varet-Vitu, Exploiter la terre. Les contrats agraires, de l'Antiquité à nos jours (pp. 333-344). París: Association Histoire et Société Rurales.

Serrao, J. (2017). Land and property rights in colonial context: An Introduction, Portuguese Journal of Social Science, $16,2,135-142$.

Serrao, J. y E. Rodrigues, (2017). Migration and Accomodation of Property Rights in the Portuguese Easterne Empire, Sixteenth-Nineteenth Centuries. En R. Congost J. Gelman y R. Santos (Eds.), Property Rights in Land. Issues in Social, Economic and Global History. Londres y Nueva York: Routledge, 9-31.

Tell, S. (2011). Títulos y derechos coloniales a la tierra en los pueblos indios de Córdoba. Una aproximación desde las fuentes del siglo XIX. Bibliographica Americana, 7, 201-221.

Teruel, A. (2005). Estructuras agrarias comparadas: La Puna argentina y el sur boliviano, a comienzos del siglo XX. Mundo Agrario, 6, 11. Recuperado de https://www.mundoagrario.unlp.edu.ar/article/view/v06n11a06

Teruel, A. (2016). El Marquesado del Valle de Tojo: patrimonio y mayorazgo. Del siglo XVII al XX, en Bolivia y Argentina. Revista de Indias, LXXVI, 267, 379-418.

Teruel, A. (2019). Adaptarse para resistir. El reclamo de tierras en una región de los andes argentinos en la primera centuria republicana. Caravelle, 112, 109-122.

Vallejo, R. (1982). Une histoire en construction. Approche marxiste et problématiques conjoncturelles. París: Gallimard Le Seuil.

Vallejo, R. (1992). Redención y pervivencia del foro durante la desamortización de Mendizábal (1836-1854). Anuario de historia del derecho español, 62, 477-500.

Vallejo, R. (2001). Reforma tributaria y fiscalidad sobre la agricultura en la España liberal, 1845-1900. Zaragoza: Prensas Universitarias de Zaragoza.

Vilar, P. (1962). La Catalogne dans l'Espagne moderne. Recherches sur les fondements économiques des structures nationales. París: SEVPEN. 
Villares, R. (1989). Els foros de Galícia. Uns quants problemes i comparacions. Estudis d'història agrària, 7, 161-185. Villares, R. y X. L. Díaz-Castroverde (Eds.) (1997). O conflicto foral nos séculos XVII e XVIII. Ourense: Xunta de Galicia-Caixa Ourense.

Viret, J.-L. (2014). Héritage, famille et liberté de disposer. Le régime castillan à la lumière des régimes coutumiers français. Obradoiro de Historia Moderna, 23, 9-34.

von Wobeser, G. (1980). San Carlos Borromeo. Endeudamiento de una hacienda colonial (1608-1729). México: Universidad Nacional Autónoma de México.

von Wobeser, G. (1983a). La formación de la hacienda colonial. México: Universidad Nacional Autónoma de México. von Wobeser, G. (1983b). El uso del agua en la región de Cuernavaca, Cuautla, durante la época colonial. Historia Mexicana, XXXII, 4, 467-495.

von Wobeser, G. (1994). El crédito eclesiástico. Siglo XVIII. México: Universidad Nacional Autónoma de México.

Widmer, R. (2009). Los comerciantes y los otros. Costa chica y costa de sotavento, 1650-1820. México: Proyecto Afrodesc.

Young, A. (1860). Voyages en Italie et en Espagne pendant les années 1787 et 1789. París: E. Guillaumin.

Young, A. (2009) [1931]. Voyages en France. París: Editions Tallandier.

Zei, E. (2018). Emphyteotic Practices and Relations of Power: An Approach of Social Conflicts in the Greek Archipielago, 17th-18th Centuries. En R. Congost y P. F. Luna (Eds.), Agrarian Change and Imperfect Property: Emphyteusis in Europe (16th to 19th centuries) (pp. 287-296). Turnhout: Brepols.

\section{Notas}

1 Optamos por esa formulación, posesión o dominio, dejando de lado la de "derechos de propiedad", porque pensamos que esta última puede inducir a confusión, al utilizar "propiedad”, que si bien se emplea bajo el Antiguo Régimen (a menudo en plural, o si no como sinónimo de propiedad de la persona para poseer), traduce un sentido diferente del actual. Una fórmula como "derechos de propiedad" (a veces como traducción directa de property rights) puede ser equívoca, cuando se la utiliza sin interrogarla para saber de qué se está hablando; peor aún, cuando se la transporta con mayor o menor lejanía en el tiempo y la geografía, pensando que puede significar lo mismo, hoy y ayer, aquí y allá.

2 Por ello queremos poner de relieve los trabajos pioneros de Gisela Von Wobeser y especialmente su contribución sobre la hacienda San Carlos de Borromeo (Von Wobeser, 1980, 1983a).

3 El asunto engloba la articulación entre las normas coloniales, su aplicación por conquistadores y colonizadores y la reacción de las sociedades prehispánicas, en destrucción y restructuración (Assadourian, 1982, 1991, 1994; García, 1992; Menegus, 2009; Mumford, 2012). Sobre posesión y transmisión de herencia en la península ibérica, Marcos, 1999; Ferrer, 2007; Viret, 2014. En cotejo, por ambos lados del Atlántico, Rey Castelao \& Cowen, 2017. Estamos en procesos coloniales, de conquista y opresión, y no de articulación armoniosa de cohabitaciones, o presuntos "pluralismos".

4 Los estudios sobre desamortización y desvinculación de la posesión (y sus capitales), importantes para la península ibérica, han tenido un desarrollo desigual en el continente hispanoamericano.

5 Aun cuando sepamos que la concentración propietal actual de tierras responde a objetivos diferentes de las concentraciones anteriores. Usamos el neologismo propietal como adjetivo para evocar la posesión que instaura la sociedad "moderna" y distinguirla de las anteriores (Luna, 2006).

6 Se conocen las limitaciones sociales de las antiguas reformas y la asimilación que han efectuado la teoría y la práctica económicas actuales de la "reforma agraria" como útil de gestión y cambio de regímenes agrarios bloqueados, propiciando "reformas agrarias con ayuda del mercado" (Luna, 2016).

7 Podían incluso anular el desdoblamiento y "reunir" ambos dominios, es decir "el útil con el directo", el inferior regresando al superior (de donde se había desprendido), fundiéndose otra vez con él, o en él.

8 Pudo ocurrir que el dueño directo, civil o eclesiástico, exigiera al útil que recuperase a su costa ciertas piezas de tierra, ocupadas por terceros sin autorización del dueño directo (Lemeunier, 1989).

9 Algunos casos del siglo XIX ya nos habían mostrado que la transformación de tierras indígenas en tierras fiscales y su cesión enfitéutica eran una primera fase para su expropiación (Madrazo, 1990), o el avance del latifundismo. Lo que no se distinguía de ciertos usos de la enfiteusis del siglo XVI, con poseedores que transformaban en cuasi-enfiteusis las tierras arrendadas de grupos indígenas, asegurando luego el despojo definitivo (Assadourian, 1991; Von Wobeser, 1983b). Ver nota 30.

10 Una de las frecuentes confusiones se relaciona con arrendar y arrendamiento, cuyo significado era estrictamente ofrecer algo a cambio de una renta (Cobarrubias, 1611). Sin situar críticamente el vocabulario de notarios y protagonistas, se les 
dio el sentido de cesión a corto plazo, como en la actualidad, cuando lo que entonces significaban era sólo la transferencia del bien contra una renta, sin precisar duración, muchas veces como cesión del dominio útil. Ya ocurrió en espacios ibéricos: detrás de arrendar y arrendamiento se hallaban ocultos verdaderos contratos y prácticas enfitéuticos de cesión de dominio útil, los que fueron progresivamente detectados por los historiadores en los archivos (Lemeunier, 1989). Son experiencias útiles para estudios sobre nuestro continente. Idem de la idea de que la enfiteusis se aplicaba sobre todo a las tierras de calidad inferior (Macera, 1966).

11 La coyuntura era el modo en que funcionaban los mecanismos de la estructura (para confirmarla o modificarla), según la clásica fórmula de Ernest Labrousse (Charle, 1980).

12 Los "hombres ilustrados" del siglo XVIII hablaban de la enfiteusis como forma casi "natural" de las relaciones entre los hombres y la tierra. En Jovellanos había una suerte de "utopía asturiana” en su percepción nobiliar de las relaciones sociales. El foro asturiano era una "transición permanente" entre rurales, sin excluir ajustes bruscos (Luna, 2006). Un enfoque similar (siglo XIX) en Cárdenas, 1873.

13 Hasta muy tarde en el siglo XX (Congost, 2000), sin hablar de sus eventuales mutaciones por venir.

14 No sólo por razones teóricas sino sobre todo por el uso de las fuentes (para posesión y transmisión de bienes inmuebles), hay que distinguir entre los censos consignativos y los enfitéuticos, unos relativos a la compraventa de rentas y otros a la cesión de bienes raíces, evitando confinarlos todos dentro de las operaciones de crédito monetario (Colmenares, 1974, 1975; Ferreira, 1999).

15 Podía ser el mismo dueño directo (o cuasi-poseedor directo) quien careciera de capitales para la explotación de la tierra y que optara por cederla en útil a enfiteutas (Ferrer, 1989; Pérez-Picazo, 1989).

16 Un proceso inédito: anexión de las tierras americanas al dominium del rey (declarativa y práctica), su cesión en posesión plena a los colonos (desde las formas caóticas de la conquista hasta su codificación legal) y las concesiones a los grupos sobrevivientes de indígenas o los aliados de la conquista (en posesión plena al inicio, luego no, sin garantía alguna contra usurpaciones). Ver Assadourian, 1991. Desde una óptica jurídica, para el Río de la Plata, Levaggi, 2012. Ver también Mariluz, 1970, 1978.

17 Algunos casos detectados no parecían alejarse de la cesión colectiva de dominio, efectuada por el rey de Castilla a comunidades o agrupamientos indígenas, y del goce de éstos como "censualistas" (Assadourian, 1991; García, 1992; Menegus, 1992, 2009). Queda por examinar la formación de las misiones jesuitas en América, como creación de centros de poblamiento, respecto al arrendamiento de las tierras adquiridas en dominio directo, u otras (López, 2013). Idem de la práctica jesuita de explotación económica de tierras como dueños útiles (en función del tipo de producto deseado), cuando no lo era gracias a esclavos o indios adscritos (Macera, 1966; Colmenares, 1969).

18 Los "espacios jurídicos peninsulares" y su influencia respectiva, de prácticas consuetudinarias (y de práctica a secas), llegaban a América con la diversidad de orígenes de sus inmigrantes (Clavero, 1986); sin que hubiese necesariamente automatismos ni aplicación general de la denominada legislación de Indias o derecho indiano, cuya codificación podía incluso ser ulterior a los hechos.

19 Desde fines del siglo XVIII y sus viajes por Lombardía, Cataluña o Francia, el publicista Arthur Young vendía el "modelo inglés", diciendo - en contradicción con sus observaciones- que el desdoblamiento de la posesión o ciertos contratos, como la aparcería, se oponían al crecimiento agrícola (Young, 1860, 2009). Otros defensores de modelos y vías ineludibles han tomado la posta, hasta nuestros días.

20 Lo hacían también para resistir a la desposesión o las expulsiones que perpetraban los poseedores directos, civiles y eclesiásticos (Saavedra, 1985; Villares, 1989; Pérez-Picazo, 1989).

21 Elaborado entre 1580 y 1610. Dato útil: nunca se habla allí de "derecho de propiedad" (Comby, 1990).

22 Como en algunos contratos en la Hispanoamérica de los siglos XVI y XVII (Von Wobeser, 1983b).

23 F. Boudjaaba (2018) lo ha hecho con la fieffe, en Vernon (Normandía). Una enfiteusis sobre lo construido en la superficie, que se extiende a otros bienes raíces. El contrato, que pareció satisfacer a ambos dominios, no sobrevivirá al Código Civil de 1804 y desaparecerá después de 1810 .

24 Ver también, al respecto, las precisiones efectuadas en Luna \& Quiroz, 2019.

25 En Córdoba se suele hallar la enfiteusis desde el periodo colonial (Levaggi, 2012; quien la restringe a las tierras municipales y eclesiásticas). Es posible encontrar casos (y litigios) de tierras de haciendas, cedidas en enfiteusis en siglos anteriores, con un poseedor del siglo XIX (ya presunto propietario) pagando el canon enfitéutico a los descendientes de los antiguos dueños directos (Macera, 1976). Por lo que resulta indispensable una lectura (o relectura) atenta de las fuentes documentales.

26 Un Código de liberales hipotéticamente partidarios de la enfiteusis, los que sin embargo, al momento de la práctica, optaron por favorecer la absorción del dominio útil por el directo y “perfeccionar” la propiedad. Lo que también ocurrió en otros lugares, por ejemplo, en la América latina decimonónica.

27 Investigaciones recientes, sobre la expansión colonial portuguesa en Asia, hablan de una forma "mestiza", indoportuguesa, de práctica enfitéutica, que habría podido incluso viajar hasta los territorios portugueses de África y adaptarse a sus necesidades (Serrao \& Rodrigues, 2017; Serrao, 2017). 
28 Por ejemplo en el norte y noroeste de la península ibérica y su desenlace a inicios de la segunda mitad del siglo XVIII (Villares \& Díaz-Castroverde, 1997; Luna, 2017a).

29 Fue el caso de la enfiteusis propugnada luego de la independencia de las provincias del Río de la Plata por Bernardino Rivadavia, sus grupos aliados y su plan económico (Bagú, 1966).

30 La cuestión fue planteada por C.S. Assadourian para la Nueva España del siglo XVI, cuando unos contratos de arrendamiento a corto plazo a favor de peninsulares, firmados por autoridades indígenas (representantes de la posesión plena de comunidades o grupos indígenas, o como poseedores plenos individuales), fueron asumidos como contratos de arrendamiento a largo plazo (cuasi-enfitéuticos), antes de la usurpación definitiva de las tierras, a veces por “composición” (Assadourian, 1991).

31 Ya no eran la monarquía o sus autoridades los legitimadores de las usurpaciones; eran los nuevos estados independientes y las fuerzas criollas. Era la continuidad de una estructura de largo plazo.

32 La generalización de la enfiteusis, afirman los juristas de la Universidad de Rosario, asociada a la pacificación y la desmilitarización, se integraría dentro de un amplio proyecto de reforma agraria.

33 En el otro extremo, el landgrabbing del siglo XXI (acaparamiento mundial de tierras, desde hace dos décadas) y el renuevo del interés por la tierra, el espacio y las riquezas naturales, son nuevos dominios para la enfiteusis (otrora instrumento colonial europeo). Ahora es fomentada por los Estados de las descolonizaciones, en África, para atraer capitales, garantizando duración, control y posesión, aunque en detrimento de las poblaciones autóctonas (Luna, 2016; Béaur, Congost, Luna, 2018).

34 A lo largo del siglo XVIII, se observan en Asturias a instituciones eclesiásticas que imponen la locación contra el foro enfitéutico y la respuesta rural restaurando foros (Luna, 2018). La capacidad o incapacidad de generalizar el arriendo es un signo de la pujanza del clero, en un contexto de crisis. Señalemos el caso de las clarisas aragonesas y su recuperación del dominio útil, uniéndolo al directo, en el siglo XIX, para luego ceder sus bienes en arrendamiento y aumentar su rentabilidad (Sanz, 2004).

35 Con una memoria institucional sólida (de archivos, inventarios y apeos), conocedoras de anteriores despojos del dominio directo, a menudo con el apoyo de Roma (Marcos, 2012), numerosas entidades religiosas habían empezado al alba de la Edad Moderna a limitar (aunque fuese formalmente) la duración de posesión del dominio útil, por tres vidas de enfiteutas o soberanos, o incluso de papas.

36 Los subenfiteutas dividían su dominio útil para instalar a hijos y parientes, vender o permutar parcelas, incluyéndolas en mayorazgos o testamentos, como hicieron los primeros foreros (Luna, 2018).

37 Los conventos y monasterios gallegos presintieron que estaban perdiendo sus bienes, a pesar de ser dueños directos, cuando veían que los hidalgos gallegos (enfiteutas intermediarios), empezaban a hacer mayorazgos en donde incorporaban como suyos los bienes eclesiásticos que habían recibido en enfiteusis (Saavedra, 2018); es decir que se ponían a vincular lo que no poseían en posesión plena.

38 La fábrica del Domo (Milán) comparando sus enfiteusis con las romanas o venecianas (Barbot, 2018).

39 El mayor peso de las rentas forales y subforales (fuera del foro, dado por el forero al dueño directo) recaía sobre los campesinos o las familias subestablecidos, sobre todo los recientes (Luna, 2017a).

40 La conservación de los foreros en su posesión útil, en Asturias, Galicia y León, fue impuesta por la Pragmática de Carlos III (1763), para calmar los conflictos surgidos de la expulsión de enfiteutas y subenfiteutas (productores y campesinos), por los directos. Una medida arrancada por la correlación de fuerzas del bloque social del dominio útil (Villares \& DíazCastroverde, 1997; Luna, 2017a).

41 Como para la desamortización mexicana (Menegus, 2009; Escobar, Falcón \& Sánchez, 2017).

42 Las evidencias empíricas parecen indicar todo lo contrario (Béaur et al, 2013; Béaur \& Chevet, 2017). Jovellanos, en el siglo XVIII, deseaba que circularan los patrimonios "muertos", gracias a la enfiteusis, atendiendo al "espíritu” de las fundaciones (Luna, 2006, 2012). Pero las fuentes documentales testimonian, incluso para Hispanoamérica, no sólo de una fuerte actividad económica sino también de una activa transferencia de bienes raíces, prohibidos de intercambio, no sólo durante las coyunturas críticas o por ruptura familiar o pleitos (Teruel, 2016; Luna, 2017). Lo que nos induce a preguntarnos para el mundo hispanoamericano, más allá de las normas legales, ¿cuán muertas estaban las manos muertas durante el periodo español? o ¿cuán indivisos se encontraban los bienes vinculados?

43 Cabe señalar, por ejemplo, la reacción rural en Valencia durante el siglo XVIII, por parte de los pueblos de señorío laico o eclesiástico y su reversión a la corona (Ardit, 2012).

44 Ver el conflicto entre terrazgueros y caciques en Oaxaca (siglo XVIII), y su prolongación hasta el siglo XIX (Menegus, 2009). Sólo la variedad de enfoques y trabajos podrá darnos una respuesta efectiva.

45 El caso de la Cícladas es especialmente interesante, al combinar varios aspectos de la actividad agrícola. Se observa allí un paso casi obligatorio por la enfiteusis para lograr invertir en la tierra, con un laudemio que solo sería pagado, como un capital, si hubiese ruptura de contrato. Se le reconoce al enfiteuta la posesión de la tierra y sus mejoras, también para compensar deudas antiguas contraídas con el poseedor directo (Zei, 2018). El capital reconocido, el trabajo del enfiteuta y las mejoras incorporadas se cristalizan en la posesión de la tierra. 
46 Provocando, a mediano plazo, la insolvencia de los arrendatarios y su liquidación por deudas (Luna, 2018). O como en el Bajo Segura, la desaparición del caserío formado gracias a la práctica enfitéutica (Canales \& Muñoz, 2001, 2002); el arrendamiento a corto plazo traduciéndose en despoblamiento 